\title{
Dos nuevos documentos de Antonio de Sosa que prueban ser autor de la Topographia e Historia General de Argel: el manuscrito Add. 28366 de la British Library
}

\author{
Aurelio VARgas DíAZ-Toledo*
}

\section{Resumen}

Trabajo que da a conocer dos documentos inéditos del doctor Antonio de Sosa, compañero de cautiverio de Miguel de Cervantes. Dichos documentos, conservados en la British Library bajo la signatura Add. 28366, son una prueba fehaciente de que este escritor portugués fue el autor de la Topographia e Historia General de Argel, publicada con el nombre de Diego de Haedo en Valladolid (1612).

Palabras clave: Antonio de Sosa; documentos inéditos; Topographia e Historia General de Argel (1612); Argel; modelo de Argel; 1577-1578; cautiverio; Miguel de Cervantes.

Title: Two New Documents by Antonio de Sosa that Prove to Be the Author of Topographia e Historia General de Argel: The Manuscript Add. 28366 from the British Library

\begin{abstract}
This paper reveals an unknown and unpublished text by Dr. Antonio de Sosa, Miguel de Cervantes' companion in captivity. These documents, kept in the British Library under the shelfmark Add. 28366, are a reliable proof that this Portuguese writer was the author of the Topographia e Historia General de Argel, published under the name of Diego de Haedo in Valladolid (1612).
\end{abstract}

* Universidad Complutense de Madrid. auvargas@ucm.es / ORCID iD: https://orcid.org/00000002-1793-4040 
Keywords: Antonio de Sosa; Unpublished Documents; Topographia e Historia General de Argel (1612); Algiers; Model of Algiers; 1577-1578; Captivity; Miguel de Cervantes.

\section{Cómo citar este artículo / Citation}

Vargas Díaz-Toledo, Aurelio. 2021. «Dos nuevos documentos de Antonio de Sosa que prueban ser autor de la Topographia e Historia General de Argel: el manuscrito Add. 28366 de la British Library». Anales Cervantinos 53: 15-52. https://doi.org/10.3989/anacervantinos.2021.001

Desde hace ya algunos años venimos trabajando en un ambicioso proyecto cuyo objetivo fundamental es rellenar las lagunas que aún existen en torno al estudio de la presencia e influencia de la obra de Miguel de Cervantes en Portugal, especialmente en lo que se refiere al arco cronológico que abarca de los siglos XVI al XVIII ${ }^{1}$.

Gracias a esta línea de investigación, hemos tenido la enorme satisfacción de haber ido encontrando no solo documentos inéditos sino también nuevos datos sobre autores y textos lusitanos que han permanecido en el olvido durante mucho tiempo y que han ayudado a conocer mejor la transmisión y recepción cervantinas en tierras portuguesas ${ }^{2}$.

En esta ocasión, tratando de continuar uno de los apartados en que hemos dividido nuestro proyecto de investigación, basado en describir el entorno portugués de Miguel de Cervantes, nos disponemos a sacar a la luz un documento de uno de los personajes lusitanos más ilustres con quien se encontró durante su cautiverio en Argel, el eclesiástico Antonio de $\mathrm{Sosa}^{3}$. Se trata de un papel manuscrito cuyo máximo interés radica en que ayuda a atribuirle inequívocamente la Topographia e Historia General de Argel (Valladolid, 1612), si bien es verdad que esta cuestión había quedado zanjada hace unos años gracias a la extraordinaria labor de un conjunto de investigadores que revitalizaron el estudio y análisis de esta obra, como veremos líneas más abajo. No obstante, no es menos cierto que se echaba en falta documentación, como la que presentamos a continuación,

1. El presente trabajo forma parte de un proyecto más amplio dedicado a la presencia e influencia de Miguel de Cervantes en Portugal durante los siglos XVI-XVIII. Dicho trabajo se articula en dos bloques. El primero está dedicado a los Vínculos de Cervantes con Portugal (A), que, a su vez, está formado por tres apartados: Datos biográficos: presencia de Cervantes en Portugal (A.1.); El entorno portugués de Cervantes (A.2.); y Presencia de Portugal en la obra cervantina (A.3.). El segundo bloque lo dedicamos a la Difusión e influencia de Cervantes en Portugal (B), que está constituido por tres partes: Transmisión de obras cervantinas en Portugal: manuscritos e impresos (B.1.); Traducciones de obras cervantinas al portugués (B.2.); y la Recepción de la obra de Cervantes en Portugal (B.3.).

2. Véanse a este respecto algunos de nuestros últimos trabajos en el apartado de bibliografía citada.

3. La noticia del descubrimiento de este texto la dimos durante el $X$ Congreso Internacional de la Asociación de Cervantistas (Madrid, 3-7 de septiembre de 2018), celebrado en la Facultad de Filología de la Universidad Complutense de Madrid. Agradecemos a José Manuel Lucía Megías y a Emilio Sola su lectura atenta y sus oportunas recomendaciones para mejorar este trabajo. 
que ayudara a probar algunos elementos en la elaboración del texto más allá de los que había podido suministrar la propia experiencia vital de Sosa. Un documento cuya comparación con la Topographia aporta datos fehacientes de que solo Antonio de Sosa podía esconderse tras la redacción de la mayor parte de la obra, aparte de que, por el simple hecho de ofrecer información sobre la ciudad de Argel entre 1577 y 1578, ya es de por sí de un enorme valor histórico.

La vida de Antonio de Sosa es tanto o más apasionante que la de cualquier otro personaje del siglo XVI. Portugués de nacimiento, al margen de varios homónimos documentados en los archivos universitarios de Salamanca o Coimbra $^{4}$-alguno de los cuales bien pudiera ser nuestro biografiado-, las primeras referencias más o menos seguras de su existencia las encontramos en 1571, cuando firmó como «teólogo» una petición dirigida a la Cámara de Castilla con el fin de ser naturalizado ciudadano de Castilla ${ }^{5}$, sin que sepamos muy bien las causas que le indujeron a ello. Además de experto en teología, sabemos que, gracias a otros documentos autógrafos, firmaba también como «Doctor Sosa», lo que nos indica su condición de doctor in utroque iuris, es decir, en derecho canónico y civil, tal y como afirma la investigadora Garcés (2005b, 137).

Tres años más tarde lo encontramos en el entorno de D. Juan Orozco de Arce, inquisidor en la ciudad de Palermo y obispo, primero en Siracusa, y después en Catania desde 1574 hasta su muerte dos años después ${ }^{6}$. Gracias a él ocupó el cargo de vicario en un primer momento en Siracusa y después en Catania $^{7}$. Tras el fallecimiento de su protector el 28 de marzo de 1576, Sosa solicitó a Felipe II ser deán de la catedral de Agrigento y con este fin adjuntó una carta de recomendación del duque de Terranova, presidente del reino

4. Salamanca. Archivo de la Universidad (AUSA), 568, fol. 65v; Salamanca. AUSA 270, Libros de Matrículas, 1546-1547, fols. 31r-32r-35v; Coimbra. Arquivo da Universidade, Livro de Actos e Provas de Curso, 1437-1550, f. 171v.

5. Simancas, Archivo General (AGS), Cámara de Castilla, leg. 404-90, año 1571: «El Dr. Sosa Teólogo»; Archivo General del Ministerio de Asuntos Exteriores (AMAE), embajada de España ante la Santa Sede, leg. 35, fols. 133-135. Bula papal de Gregorio XIII para el doctor Antonio de Sosa.

6. De su experiencia en Sicilia contamos con el testimonio que él mismo ofrece en el Diálogo de la captividad, división 5, en donde alude a su estancia en esta isla: «Sosa: [...] pues os diré la verdad, que en los años que estuve en aquel reino de Sicilia, como sabéis, no solo en Siragusa y en Catania, pero en Augusta, Letim, Franca Forte, Melitelo y Mineo, y en otros lugares que están al pie de aquel famoso y altísimo monte Etna [...] vi y tuve en mis manos y en mi poder cantidad de muelas y de huesos humanos de toda suerte que hallaron en algunas cuevas a que llaman en aquella tierra grutas...» (Haedo 1929a, 41).

7. Rocco Pirri, Sicilia Sacra disquisitionibus et notitijs illustrata: ubi libris quatuor postquam de illius patriarchia, et metropolita disquisitum est, à christiane religionis exordio ad nostra usque tempora cuiusque praesulatus, maiorumque beneficiorum institutio, archiepiscopi, episcopi, abbates, priores, singulorum iura, priuilegia, praeclara monumenta, ciuitates dioeceseon cum praecipuis earum templis, religiosisque familijs atque viri siculi vel sanctitate, vel doctrina illustres continentur, explicantur (Palermo, Ex tipographia Petri Coppulae, 1633-47). Syracusanae Ecclesie Notitia II, lib. III, XC, fol. 641; Simancas. AGS, SP, leg. 3. Consultation of the Council of Italy. Según Garcés (2011, 58-59), «he [Orozco de Arce] appointed as vicar, among others, "Dr. Antonio de Sosa, lusitano"». 
de Sicilia, en la que este elogiaba sus estudios así como sus cualidades personales. El monarca accedió a ello y le nombró tal el 26 de octubre de $1576^{8}$.

Al año siguiente, el primero de abril de 1577, cuando se disponía a tomar posesión de su nuevo cargo acompañado de su hermana viuda, un sobrino de corta edad y tres criados, la galera San Pablo de la Orden de San Juan de Malta en que se habían embarcado en Barcelona con rumbo a La Valeta, cayó en manos de los corsarios argelinos muy cerca de la costa de Cerdeña, en la isla de S. Pedro. El capitán de la escuadra corsaria era Arnaut Mamí, el mismo que dos años atrás había capturado también a los hermanos Cervantes. En el reparto de los cautivos, al judío Mahamed (o Ka'id Mamet), un renegado convertido al islam con mucho poder dentro de la sociedad argelina de la época, gobernador de Argel en alguna ocasión en ausencia de Ramadán Bajá y que había participado, entre otras cosas, en la conquista de La Goleta en 1574 (Gayangos 1875) ${ }^{9}$, le correspondió Antonio de Sosa.

A partir de entonces, una de sus varias ocupaciones consistirá en hacer todas las gestiones pertinentes para salir de allí, a pesar de las dificultades que entrañaba, pues se le consideró desde un principio un cautivo de rescate y su precio ascendió en un primer momento a 15000 ducados. Para ello, movió todos los hilos a su disposición tanto para conseguir dinero como para buscar algún otro remedio que le ayudara a liberarse. Así, por ejemplo, desde 1577 trató de que la corte española aceptara un canje de rehenes entre él y un renegado corsario llamado Arnaut, que se hallaba encarcelado en Nápoles con una pena de quince años (Garcés 2011, 63). Este fue rechazado por el virrey de Nápoles, Juan de Zúñiga, debido a que el prisionero tenía gran experiencia en la navegación así como en las costas italianas, y era un peligro potencial para los ejércitos cristianos (Sola y Peña 1995, 181-182).

Mientras tanto, hizo que su hermano carmelita, fray Diego de Sosa, entrara en contacto directamente con el rey Felipe II para que buscara la manera de liberarlo, haciéndole entrega al mismo tiempo de un poder con el objeto de reunir dinero para su liberación procedente del deanato de Agrigento, pese a que aún no había podido asumir su cargo. En relación con este asunto, consiguió asimismo que su compatriota y procurador, el carmelita Giacomo di Spiritu Sancto, presentara una bula papal confirmatoria en la catedral de Agrigento el día 31 de marzo de 1579 con el objeto de tomar posesión del deanato en nombre de Sosa y gozar, así, de las prebendas derivadas del cargo, entre ellas el dinero que le correspondía por su salario y que buscaba utilizar para su propia liberación (Garcés 2011, 62).

En lo que respecta a la intervención del monarca, que se involucró personalmente debido a la gran estima que le tenía, se han conservado algunas cartas con datos relativos a las gestiones sobre su rescate desde los primeros

8. Simancas. AGS, S.P. (Secretarías Provinciales), libro 940, fol. 102r-102v. Presentación a su favor para el deanato de la iglesia mayor de Agrigento, de Real Patronato, que ha vacado por muerte de D. Pedro de Alagona. El Pardo, 28 de octubre de 1576.

9. Aparece bajo el nombre de Cayto Mahamete. 
días de su cautiverio hasta el verano de 1581. Así, por ejemplo, el 8 de septiembre de 1577 se dirigió a Marco Antonio Colonna con el fin de que usase 500 escudos de la paga de Sosa relativa a su cargo de Agrigento no solo para su rescate sino también para el de su familia ${ }^{10}$. Esta cantidad, muy insuficiente, se vio incrementada el 12 de marzo de 1580 hasta alcanzar la cifra de mil escudos, justo después de que el rey recibiera una misiva por parte de Sosa afirmándole que su amo no lo iba a liberar por menos de 12000 escudos en oro $^{11}$. Más adelante, en 1583, sabremos mediante otra misiva de Felipe II dirigida a su embajador en Roma, el conde de Olivares, que el Estado había desembolsado un total de 15000 escudos en oro por su liberación, sin que, al parecer, él llegara nunca a saberlo ${ }^{12}$.

Durante su cautiverio en Argel, Antonio de Sosa se convirtió en una figura muy destacada entre los cristianos, a pesar de la dureza de la prisión en que le había puesto su amo, quien no le dejaba casi ni salir al exterior. Ejemplos de las dificultades y penalidades que padeció allí las dejó diseminadas él mismo a lo largo de su obra, aunque es normal que enfatizara su falta de libertad y sus padecimientos con el fin de conseguir que le llegara la enorme suma de dinero que se pedía por él. Así, por ejemplo, en la División primera del Diálogo de la captividad en Argel nos cuenta a través de los ojos de su interlocutor, el también portugués Antonio Gonçalves de Torres, el mal olor de su mazmorra, su continua humedad, su estrechez y la crueldad de su amo, el alcaide Mahamet, para con él. El miserable estado en que se encontraba Sosa dará pie después a que ambos interlocutores den inicio a un intercambio de pareceres muy jugoso sobre el estado del cautiverio, la falta de libertad y los orígenes de la esclavitud en la historia de la humanidad, tan común, por otro lado, al desarrollo de los sucesivos imperios de la Historia (Haedo 1929a, 1-18) ${ }^{13}$.

A pesar de estas circunstancias adversas, a lo largo de estos años Sosa llegó a entablar una buena amistad, entre otros, con Miguel de Cervantes. Tal y como es bien conocido, aquel participó en la Información de Argel que este presentó el 10 de octubre de 1580 al padre redentor fray Juan Gil, a través del cual pretendía defenderse del potencial daño que el fraile dominico Juan Blanco de Paz le pudiera hacer en un futuro (Lucía Megías 2016, 212-222), pues le había amenazado en varias ocasiones con hacer público en la corte madrileña ese «vicio notable o escándalo de su persona» (Sosa 2014, 101), que probablemen-

10. Simancas. AGS, SP, lib. 845 , fols. 73 v-74r. El rey a Colonna, 8 de septiembre de 1577 . Sobre la familia Colonna, concretamente sobre Ascanio, véase el fundamental trabajo de Marín Cepeda (2015).

11. Simancas. AGS, SP, leg. 982. Consulta del Consejo de Italia, 12 marzo 1580.

12. Madrid. AMAE, embajada de España ante la Santa Sede, leg. 35, paq. 4, fol. 125.

13. División 2: «Porque sabe que sé yo con cuanto ha cuatro años continuos que tu suegro y mi patrón [Amud] me tiene tan atado a esta piedra, y tan cargado de cadenas, y encerrado en este obscuro aposento, que de otras tales ollas como éstas y todas guisadas de gallos roxos con sus plumas, cabezas y tripas está la fuente verde a que vosotros llamáis en morisco Alamehadar...» (Haedo 1929c, 213); División 6: «Para decirte la verdad por estar tan atado a esta piedra ha tantos años, más que un mono fugitivo, y debajo de tantas guardias y encerramiento no ví con mis ojos más de sólo a uno, que el patrón,... y porque sepas que cuanto pasa en Argel sé, y aun lo escribo como sabes todo, día por día...» (Haedo 1929c, 246). 
te tendría que ver con la blasfemia, la apostasía o incluso la sodomía, practicada habitualmente entre los turcos y los «garçones» cristianos.

Lo más curioso a este respecto es que el testimonio de Sosa es el único escrito en primera persona por la propia mano del testigo, frente a los de los otros once testigos, que contienen declaraciones verbales copiadas a instancias de Pedro de Ribera, «notario apostólico que a todo lo que dicho es presente fui con los testigos arriba declarados, y se escribió de mano ajena y lo signé y suscribí de mis acostumbrados signos, en testimonio de verdad, rogado y requerido» (Sosa 2014, 146). La causa de esta, cuando menos, particular situación nos la proporciona el propio autor al inicio de su testimonio, que lleva fecha de 22 de octubre de 1580 y que dice así: «Por causa de mi contrario y estrecho encerramiento en que mi patrón me tiene con cadenas, no he podido dar mi testimonio y deposición sobre cada uno de ellos» (Sosa 2014, 146).

Gracias también a la citada Información de Argel, conocemos con cierto detalle el transcurso del segundo intento de fuga de Cervantes, el de 1577, en el que "yo fui uno de los con que el dicho Miguel de Cervantes comunicó muchas veces y en mucho secreto el dicho negocio; y que para el mismo negocio fui muchas veces del convidado y exortado, y no se hizo cosa en el tal negocio que particularmente no se me diese dello parte» (Sosa 2014, 147). Este episodio, que pone de manifiesto un hecho incontrovertible, como es el grado de complicidad y confianza que existía entre el cautivo alcalaíno y su colega portugués, aparecerá descrito con cierto detalle en el Diálogo de los mártires. Aquí Sosa llega a configurar una imagen heroica de su amigo durante su estancia en suelo argelino (Lucía Megías 2016, 227-228), afirmando que, de haber tenido éxito en su «industria y trazas», «hoy fuera el día que Argel fuera de cristianos, porque no aspiraban a menos sus intentos» (Haedo 1612, 184r-185v). De este modo, Miguel de Cervantes pasa de ser un simple soldado a un cabecilla, un líder capaz de convertir al cristianismo a toda Argel, que era temido por el mismo gobernador Hazán Bajá, quien procedió a comprárselo a Dalí Mamí con el fin de encerrarlo en sus baños y evitar que pudiera alzarse con el control de la ciudad:

De las cosas que en aquella cueva sucedieron en el discurso de los siete meses que estos cristianos estuvieron en ella y del cautiverio y hazañas de Miguel de Cervantes se pudiera hacer una particular historia. Decía Hazán Bajá, rey de Argel, que como él tuviese guardado al estropeado español tenía seguros sus cristianos, bajeles y aun toda la ciudad; tanto era lo que temía las trazas de Miguel de Cervantes, y si no le vendieran y descubrieran los que en ella la ayudaban, dichoso huviera sido su cautiverio, con ser de los peores que en Argel había, y el remedio que tuvo para asegurarse d'él fue compralle de su amo por quinientos escudos en que se había concertado, y luego le acerrojó y le tuvo en la cárcel muchos días (Haedo 1612, 185r).

Los biógrafos cervantinos del siglo XVIII en adelante llamaron la atención de este breve episodio en la vida de Cervantes porque, además de ser el único relato en el que no se describe ningún martirio, a excepción de un pobre 
jardinero, lo usaron con el fin de crear la leyenda de que el escritor alcalaíno había logrado salvar su vida hasta en cuatro ocasiones debido a su valentía y esfuerzo, capaz incluso de enfrentarse al cruel gobernador de Argel Hazán Bajá, quien solo le condenó a ser encerrado en el baño del rey durante cinco meses «cargado de cadenas y hierros» (Sosa 2014, 98), según se lee en la pregunta XI de la susodicha Información.

Aparte de estas manifestaciones de admiración y amistad mutuas, Sosa y Cervantes compartieron inquietudes intelectuales y aficiones literarias en estos años. De hecho, hay constancia de que el segundo, que escribió durante su cautiverio una Epístola a Mateo Vázquez (Gonzalo Sánchez-Molero 2010), dos sonetos en alabanza de un libro de Bartholomeo Ruffino de Chiampery, titulado Sopra la desolatione della Goletta e forte di Tunisi. Insieme la conquista fatta da Turchi de Regni di Fezza e di Marocco (3 de febrero de 1577) ${ }^{14}$, y una carta -hoy desaparecida- dirigida al poeta siciliano Antonio Veneziano (Rico 2014; Ruta 1979), llegó a entregar al primero poesías devotas dedicadas a Jesús y a la Virgen con el fin de que le diera su ilustre opinión, tal y como se recoge de nuevo en la Información de Argel:

Y sé que se ocupaba muchas veces en componer versos en alabanza de Nuestro Señor y de su bendita madre y del Santísimo Sacramento y otras cosas santas y devotas, algunas de las cuales comunicó particularmente conmigo, y me las envió que las viese (Sosa 2014, 146-151).

Dejando de lado la vida cotidiana y las amistades en Argel, mientras las diligencias para su liberación seguían su curso y se estaban llevando a cabo en ciudades tan distantes entre sí como Roma, Madrid, Agrigento o Argel -lo que demuestra, por otro lado, el flujo de información tan interesante que se realizaba en estos años-, llegaron a la corte varias bombas informativas inesperadas que causaron enorme revuelo en las altas esferas de poder, especialmente en la curia y en la corte hispánica. Y lo sabemos hoy gracias a la enorme labor investigadora de María Antonia Garcés, quien, tras varios años consultando archivos de todo el mundo, desenterró un conjunto de documentos que atañen a momentos cruciales en la vida de Sosa, en concreto, sobre su marcha de Argel, de la que se ignoraba prácticamente todo.

Entre dichos documentos, la primera noticia sorprendente aparece en un informe redactado en italiano por un comerciante genovés con residencia en la ciudad argelina, de nombre Luis Fresco Brevez, que se lo entregó al «doctor Sosa» y al capitán Juan de Bolaños cuando partía de Argel el 5 de septiembre de 1582. Estos se lo dieron, a su vez, a Mateo Vázquez, secretario de Felipe II, incorporando una breve anotación manuscrita, fechada en Madrid el 23 de septiembre de 1582, en donde solicitaban a su destinatario se la

14. El original de Ruffino se ha perdido, pero se han conservado algunas copias, como por ejemplo la que Juan Eugenio Hartzenbusch realizó para su edición del Quijote (1863-1864). 
diese a Su Majestad y «nos avise si será en servicio se continúe» ${ }^{15}$, lo que demostraría el hecho de que tanto Sosa como Bolaños eran informadores o agentes encubiertos que solían transmitir información delicada sobre la situación de este enclave tan estratégico del norte de África, como así pone de manifiesto también el documento que vamos a dar a conocer aquí.

En cuanto al contenido del texto, informa sobre todo lo sucedido en tierras argelinas desde el día 10 de julio hasta el 25 de agosto de 1581, aunque la parte más interesante en lo que respecta a Sosa la encontramos el día 13 de julio, que dice de la siguiente manera:

\begin{abstract}
Al 13 il Caito Mamet, che era padrone del doctor Sosa, fece grandissimo rumore per la fugita del detto signore Sosa, et mando chiave per terra et fece ogni diligensa per mar ne mai ne ha saputo nova, per onde si indica sia ponto in Spagna a salvamento, et fece gitar bando che qui sello portasse li haveria datto cento doble ${ }^{16}$ (la cursiva es nuestra).
\end{abstract}

De acuerdo con esta breve nota, Antonio de Sosa había logrado escapar de la dura prisión en que le tenía recluido el judío Mahamet, quien tanto lo apreciaba que no dudó en remover cuanto tenía a su alcance para tratar de encontrarlo, ofreciendo incluso una elevada recompensa a quien lo llevase de vuelta a su presencia. Y a juzgar por su contenido, hemos de pensar que la «fugita» debió producirse unos pocos días antes del 13 de julio, ya que el informador habla de la posibilidad de que Sosa hubiera alcanzado ya tierras españolas.

Sobre este mismo asunto, en un informe del Consejo de Castilla dirigido al rey con fecha de 11 de septiembre de 1581, se habla de algunos aspectos relativos a una solicitud del propio Sosa en la que afirmaba haber abandonado Argel «no ha más de mes y medio», es decir, hacia finales del mes de julio, una fecha que no casa con la ofrecida por el comerciante genovés, quizá porque a Sosa no le interesaba dar muchos detalles sobre ello dado el oscurantismo que empezaba a tomar este y otros asuntos de su vida. Además

15. Madrid. Instituto Valencia de Don Juan, sección/ legajo: envío 62, caja 2, fols. 25-26. Madrid, 23 de septiembre de 1582. Antonio de Sosa y Luis de Bolaños. Publicada en Garcés (2012). Con respecto a Brevez Fresco, aparecen alusiones a él en la Topographia: cap. 35. Miscelánea de algunas opiniones, costumbres, usos y observancias que tienen los turcos, moros y renegados de Argel. «Usan mucho presentar algo de quien piensan sacar el doble, y, como solemos decir, dar aguja por sacar reja, y si por el presente que hacen no les dan otra cosa en cambio y remuneración, o no se la pagan, quéjanse a la justicia, y es uso y costumbre mandar la justicia que se lo pague, y esto acaeció a Luis Brevez Fresco, mercader ginovés, en el año 1579: habiéndole presentado un moro un leoncillo y no queriendo dar al que se lo presentó cuatro picos de grana, que valían más sin comparación, fué de la justicia condenado a pagar quince doblas, que son seis escudos, por el león» (Haedo 1927a, 160).

16. Relatione delle cose seguite in Algiere dalli diece de luglio sino a questo giorno $[25$ de agosto de 1581], fol. 1r, conservada en Madrid. Instituto Valencia de Don Juan (IVDJ), envío 62, caja 2, fols. 25 y 26. Madrid, 23 de septiembre de 1582. Publicada por Sola y Garcés (2012): «El 13 (de julio) el Caito Mamet, que era el patrón del doctor Sosa, organizó un grandísimo escándalo por la huida del dicho doctor Sosa; no sólo envió llave (o consignas o contraseña) por tierra sino también hizo toda diligencia posible por mar, mas no ha recibido noticia alguna, por lo que se juzga que haya llegado a España a salvo. E hizo pregonar bando de que a quien se lo trajera le había de dar el doble por ciento». 
de incidir en su pobreza, se aludía a la cantidad que había costado su liberación, en total 2400 escudos en oro, y que aún debía 1500 a mercaderes a causa de la libertad de su hermana - por 400 escudos en oro- y suya, mientras que afirmaba con pesar que no solo su sobrino había fallecido sino que además sus dos criados así como la doncella de su hermana continuaban en suelo africano ${ }^{17}$. El memorial acababa pidiendo se le diese una saca de cueros de los reinos de Castilla, hasta un total de 8000 , con la finalidad de obtener dinero para hacer frente a sus deudas ${ }^{18}$.

A partir de su marcha de Argel -a la que él nunca llama huida sino rescate, tal y como nos advierte Garcés-, el eclesiástico lusitano estuvo viviendo en la capital madrileña entre diciembre de 1581 y finales de 1582 (Pérez Pastor 1897, 235-237), tiempo durante el cual tuvo la oportunidad, entre otras cosas, de ayudar a María Ramírez con una pequeña aportación de dinero con el fin de que pudiera liberar a su hija Mariana, cautiva en Argel. Ambas no eran sino mujer e hija de su amigo el capitán Jerónimo Ramírez, compañero durante su cautiverio y uno de los interlocutores en su Diálogo de los mártires de Argel $^{19}$.

Una de las últimas referencias de su estancia en Madrid la encontramos en una carta que Sosa envió al rey el 26 de agosto de 1582, a través de la cual, además de conocer sus conexiones con figuras influyentes y bien posicionadas en la corte ${ }^{20}$, sabemos que, debido a una enfermedad, no había podido trasladarse a Lisboa con el fin de agradecerle en persona todo lo que había hecho con respecto a su libertad ${ }^{21}$.

En cuanto a la segunda bomba informativa, todavía más impactante, tiene que ver con las graves acusaciones que se vertieron sobre Antonio

17. Simancas, 11 de septiembre de 1581, AGS, Cámara de Castilla (CC), leg. 510, fol. 26. Según Garcés $(2011,65)$, «A consultation sent to the king by the Council of Castile on 11 September 1581, regarding Doctor Sosa's liberation, is worth citing now. The document summarizes a petition from Sosa, who stated he had left Algiers a month and a half earlier: «where his ransom cost him 2400 gold escudos, which he collected principally thanks to the charity Your Majesty bestowed on him, and, in spite of this, he is still owing almost 1500 gold escudos to merchants for his own ransom and that of his sister, the interests of which are increasing day by day».

18. El doctor Sosa también pide al rey que le prorrogue por seis meses más la licencia de 3000 cueros que le había dado en diciembre pasado (1581) para que los sacase de Sevilla a cualquier otra parte o reino y pudiese así ayudar a pagar el rescate suyo y el de su hermana y criados (Simancas. AGS, CC. Memoriales, leg. 539, doc. 357. Memorial inédito de Antonio de Sosa publicado en Marín Cepeda (2010); Simancas. AGS,CC. Memoriales, leg. 510, doc. 262: memorial inédito elevado a la Cámara de Castilla el 11 de septiembre de 1581. Al secretario Juan Vázquez. Su Majestad manda se vea esto y se le consulte lo que parescerá. Licencia para tres mil cueros, publicada en Marín Cepeda (2010).

19. Protocolo de Juan de Yarza, 1581. Madrid, 5 de diciembre de 1581. Obligación del Doctor Antonio de Sosa, clérigo, vecino de Madrid, de pagar á Maria Ramirez 1320 reales que ha dado para el rescate de su hija Mariana Ramirez, cautiva en Argel. Recogido en Pérez Pastor (1897, 235).

20. Así, por ejemplo, se alude a Antonio Mauriño de Pazos, Presidente del Consejo de Castilla y visitador de la Inquisición española en Sicilia (1574-1577), a Hernando de Vega, Presidente del Tesoro Real, o al secretario Juan Vázquez de Salazar. Véase: Londres. British Library, Add. 28342, fols. 8-11.

21. Londres. British Library, Add. 28342, fols. 421r-421v. Madrid, 26 de agosto de 1582. Agradecimientos de Sosa al rey por el dinero dado para su liberación. 
de Sosa estando todavía en la capital del reino. En un pleito criminal ante la audiencia arzobispal de Madrid ${ }^{22}$, figura una sentencia firme con fecha de 25 de noviembre de 1582, en la que se le condenaba por los siguientes delitos. Por un lado, se le acusaba de apostasía por haber abandonado la Orden agustina y sus votos de castidad y celibato sin haber pedido una dispensa papal -algo imprescindible-, haciéndose pasar desde entonces por un sacerdote y teólogo. Por otro lado, se revelaba que su supuesta hermana era, en realidad, su amante, y que su «sobrino pequeño» no era otro sino su propio hijo. Entregado al superior de la Orden en Portugal, fr. Agustín de Jesús, que casualmente estaba en Madrid, fue enviado de inmediato a Roma con el objeto de buscar la redención del Papa Gregorio XIII y evitar así la ira regia. Este aceptó las disculpas de aquel, pero a cambio, como castigo, debía volver a tierras argelinas durante un período de seis meses con el fin de consolar a los cautivos cristianos ${ }^{23}$. Suponemos que la sola idea de volver allí le tuvo que parecer descabellada y a todas luces muy peligrosa, ya que ello implicaba que pudiera ser descubierto e incluso asesinado. La respuesta de Sosa, que finalmente no regresó a Argel, consistió, no obstante, en un relatorio escrito en latín a través del cual no solo exponía la situación de los cautivos cristianos en Argel, sino que además proponía algunos remedios para salvar a quienes eran tentados a perder su fe 24 .

En lo que se refiere al monarca castellano, la noticia de la marcha tan precipitada de Sosa de Madrid tuvo que causarle cierto malestar, muy especialmente después de todo cuanto había hecho por su carrera, y tanto fue así que decidió nombrar, el 17 de julio de 1583, a Silvestre Mauroli nuevo deán de la catedral de Agrigento en sustitución de $\operatorname{Sosa}^{25}$ y en oposición a la autoridad papal ${ }^{26}$. Esto hizo que durante un tiempo hubiera dos pretendientes nombrados para una misma vacante, es decir, el doctor Sosa por parte del Papa, y Mauroli por parte del rey. Una circunstancia que dejaba traslucir, entre otras cosas, las luchas de poder que mantenían Felipe II y el Santo Padre por el control en la elección de los cargos eclesiásticos. A pesar de los intentos del soberano por hacer que su antiguo protegido abandonara el cargo, Sosa hizo oídos sordos y permaneció en la catedral de Agrigento, de cuyo

22. AMAE, Embajada de España ante la Santa Sede, leg. 35, paq. 4, fol. 143. Pleito criminal ante la audiencia arzobispal de Madrid, contra el Doctor Sosa.

23. Gregorio XIII publicó una bula con este fin: AMAE, Embajada de España ante la Santa Sede, leg. 35, fols. 133-35.

24. Roma. Archivo Segreto Vaticano, Misc. Arm. V, cap. 4, n. 68: Antonii de Sousa supplicatio sup modo iudauci religiones catholica et cap infideles.

25. Simancas. AGS, S.P. (Secretarías Provinciales), libro 943, fol. 128v. Presentación que hace a su favor para el Deanato de la Iglesia mayor de Agrigento, que ha vacado por cesantía del Dr. Antonio de Sossa, Madrid, 17 de julio de 1583.

26. AMAE, Embajada de España ante la Santa Sede, leg. 35, paq. 4, fol. 125. El rey a Olivares. 
deanato tomó posesión durante el verano de $1584^{27}$ y no lo abandonaría hasta su muerte en 1587 (Pirri 1633-1647, 641) 28.

Establecido en tierras sicilianas hasta el final de sus días, Antonio de Sosa debió coincidir en Agrigento durante, al menos, dos años con Diego de Haedo (?-5/7/1608), antiguo inquisidor de Valencia, Zaragoza y Sicilia, y desde octubre de 1584 nuevo obispo de Agrigento, aunque no tomaría posesión de su cargo hasta el 31 de marzo de 1585. Y a juzgar por algunos documentos de la época, ambos se conocieron y colaboraron juntos en el quehacer diario de la catedral ${ }^{29}$. Un dato este importante porque ayuda a comprender un poco mejor la historia editorial de la Topographia e Historia General de Argel, cuya autoría ha dado tanto que hablar a los estudiosos desde que fuera publicada en Valladolid (Diego Fernández de Córdoba y Oviedo, a costa del mercader de libros Antonio Coello), en 1612, bajo el nombre de Diego de Haedo. El origen de esta falsa atribución vino, no obstante, de la mano de otro homónimo, sobrino del anterior, que fue quien se encargó de llevar a la imprenta dicha obra y cuya carta-dedicatoria, con fecha de 25 de diciembre de 1605 , la atribuyó a su tío, tal y como se puede ver a continuación en una cita tantas veces aludida:

\begin{abstract}
Entre otras muchas razones que me mueven, Ilustríssimo señor, para dedicar a V.S.I. estos escritos, dos tengo por más principales. La primera es que en su persona, sin lisonja alguna, caben muchas alabanças y excelencias, pero es tan modesto y humilde V.S. que las aborrece y huye dellas como de ofensas. Y assí suplico a V.S. me dé licencia para dezir algo, ya que no sea todo.

La segunda es averlos compuesto V.S. siendo informado de Christianos cautivos, especialmente de los que se contienen en los Diálogos, que estuvieron muchos años en Argel, y avemoslos (sic) entregado, estando yo en Palermo en su servicio, aunque en borrón: de manera que sin el trabajo $y$ diligencia que en ellos he puesto, dándoles la última forma y essencia, no se podian imprimir, ni sacar a luz; y pues son de V.S.I., se los buelvo $y$ ofrezco para que sean recibidos y estimados como el mucho valor del autor merece, en los cuales se conocerá el zelo santo que en V. S.I. mora, compadeciéndose de los inmensos trabajos que los Christianos cautivos padecen en Argel, y de los grandíssimos daños que a la Christiandad de aquí se le siguen, manifestándolos al mundo en esta historia, para que todos los que fueren piadosos se muevan a buscar su remedio (la cursiva es nuestra) (Haedo 1612, [3v]).
\end{abstract}

27. Agrigento. Archivio Diocesano, reg. 1578/79, fol. 399r; Agrigento. Archivio Diocesano, reg. 1584/1585, fols. 424v-425r: «Didacus de Haedo episcobus agrigentinus, Nos Doctor Don Antonio Sosa decanus Cathedralis ecclesie agrigentine (1585)».

28. He [Orozco de Arce] appointed as vicar, among others, «Dr. Antonio de Sosa, lusitano», Agrigentinae Ecclesie Notitia III, lib. III, fol. 772. Sobre la muerte de Antonio de Sosa, que dejó 8 onzas como huellas mortales: «Antonius Sola [sic, Sosa] Hispanus, decessit 1587», recogido en Garcés $(2011,75)$.

29. Agrigento. Archivio Diocesano, reg. 1584/1585, fols. 424v-425r: «Didacus de Haedo episcobus agrigentinus, Nos Doctor Don Antonio Sosa decanus Cathedralis ecclesie agrigentine (1585)»; Agrigento. Archivio Diocesano, reg. 1584/1585, fols. 319r-320r. 
A través de esta referencia se saca la conclusión de que el obispo fue el único autor de la obra y que había utilizado los relatos -orales o escritos- de aquellos excautivos procedentes de Argel con el fin de organizar, estructurar y dar forma literaria a un texto exhaustivo y muy detallado de la historia de este país, así como de las calamidades sufridas por los cristianos en los «baños» turcos. De los autores de los mencionados relatos, «especialmente de los que se contienen en los Diálogos, que estuvieron muchos años en Argel», hasta donde sabemos hoy día, no tenemos constancia de que ni Antonio González de Torres, ni Jerónimo Ramírez, ni mucho menos el judío Amud, los otros tres interlocutores de sendos diálogos de la obra junto a Antonio de Sosa, hubieran estado en Sicilia para hacer partícipes a los Haedo de su experiencia en Argel, aunque no habría que descartarlo en absoluto, sobre todo en lo que se refiere a los dos primeros. Por ello, es posible que se estuviera refiriendo de manera encubierta al eclesiástico portugués, si bien es verdad que esta opción no deja de ser una mera conjetura. Por su parte, el sobrino Haedo no dejaba de ser más que el encargado de pasar a limpio y dar forma al «borrón» que su tío le había entregado, así como de editarlo, si bien es verdad que «sin el trabajo y diligencia que en ellos he puesto, dándoles la última forma y essencia, no se podían imprimir, ni sacar a luz».

En lo que a este sobrino se refiere, viajó a Sicilia en 1593 para trabajar en calidad de secretario junto a su tío, que había sido nombrado nuevo arzobispo de Palermo en 1589, aunque no tomaría posesión de su puesto hasta 1595. De este modo, el sobrino permaneció primero dos años en Agrigento y después cuatro más en Palermo, hasta junio de 1599, momento en el cual volvió a su tierra para convertirse al cabo de los años en abad de la abadía de Frómista (1604-1607) y después de la de Zamora (1607-1613), hasta su fallecimiento el 19 de marzo de 1613.

Al parecer, durante su estancia en Palermo, su tío solía acoger en su casa a excautivos procedentes de las prisiones musulmanas que acostumbraban a hacer aquí un alto en su camino de vuelta a casa, y en cuyas tertulias relataban con pelos y señales cuanto les había sucedido hasta lograr su liberación. Es más, en la carta-dedicatoria el sobrino afirmaba que, dadas las virtudes de su tío, este socorría a menudo a los más desfavorecidos y daba elevadas sumas de dinero con la finalidad de rescatar a cautivos cristianos de Argel:

Y aunque la nobleza de la sangre de V.S. I. es mucha -sin mentira ni lisonja-, muy mayor es la de sus virtudes, que son el verdadero hornamento del hombre, en cuya persona resplandecen con grande eminencia, especialmente la de la caridad, que se ve en V. S. tan ferviente como en otro S. Martín, que para poder mejor socorrer pobres y acudir al rescate de los Christianos cautivos de Argel, con muy gruessa cantidad de dineros y a la hospitalidad de los passajeros, que a esse reino acuden de otros muchos, se desentraña y lo quita V.S.I. del regalo de su persona y ornato de su palacio arçobispal como varón de misericordia, lo cual haze a V. S. un muy calificado y gran príncipe eclesiástico, cual Dios tenía guardado para el bien de essa su Iglesia (Haedo 1612, [4r]). 
El caso más conocido a este respecto es el del toledano Diego Galán, quien describe en su Relación del cautiverio y libertad de Diego Galán, natural de la villa de Consuegra y vecino de la ciudad de Toledo, el encuentro que mantuvo en el palacio arzobispal de Palermo con ambos Haedo. Allí, además de recibir algo de dinero para poder volver a su casa, les contó de primera mano sus peripecias y calamidades durante su largo cautiverio en Argel y Constantinopla, ciudad esta última de la que muy pocos lograban salir (González Castrillo 2011), y su viaje de vuelta a su Consuegra natal. Galán fue hecho prisionero en 1589, con catorce años de edad, después de haber sido engañado por un soldado «taimado bellaco» que, mediante vanas promesas, le hizo entrar junto a otro joven en una saetía con rumbo a Orán que terminó cayendo en poder del corsario Arnaut Mamí. Al mismo tiempo, informa sobre la gran amistad que llegó a entablar con el sobrino Haedo, a quien le unía el ser originario de Toledo. Además, este último acabó casándose en un pueblo de la comarca, Orgaz. Con él se embarcaría más adelante, en 1599, para partir definitivamente de Sicilia con rumbo a su tan ansiado hogar. Estas son las palabras de Galán:

Luego me vine a un lugar llamado Jermine ${ }^{30}$ que dista veinte y cuatro millas de Palermo, y de allí pasé a él, do hallé muchos soldados españoles, y uno que se llamaba Pacheco me recogió en su camarada y me llevó en casa del obispo que se llamaba don Diego de Haedo, y tenía un sobrino que se llamaba como él, y era natural de Toledo, que después acá se casó en Orgaz, y me acomodé con él en el ínterin que hallase pasaje, y me daba de comer muy bien, y un día habló a su tío, diciéndole cómo yo era español que venía de cautiverio, y así que me socorriese en alguna cosa para pasar adelante, y luego llamó al mayordomo y le dijo que a la partida me diese para ayuda al camino. Luego di un memorial al señor duque de Maqueda $^{31}$, que era virrey de aquella tierra y al dársele me preguntó que de dónde era. Yo le dije que de Toledo y se holgó mucho por ser de la tierra. En fin, el memorial lo remitió a los señores del patrimonio para que se dieran diez ducados, que es lo que se acostumbra a dar a los cautivos, y ellos lo hicieron tan bien, que después de haberme traído con palabras no me dieron nada. Estuve allí tres semanas, y luego fui a Monreal ${ }^{32}$, donde hay otro arzobispo más rico que el de Palermo, y el lugar, aunque pequeño, es de muchas conveniencias. Luego, al cabo de ocho días llegó a Palermo una barca con ocho cautivos que habían huido, con los cuales venía un portugués de Lisboa, a quien yo conocía porque su amo era muy amigo del mío, y luego que me vio, me abrazó y contó su buen suceso. Y habiendo estado allí muchos días sin haber embarcación, nos determinamos él y yo de venirnos por tierra a la ciudad de Trápana ${ }^{33}$, que es puerto más pasaje-

30. Tal vez Termini Imerese, al este de Palermo.

31. Bernardino de Cárdenas y Portugal (Torrijos, 1553- Palermo, 1601), III duque de Maqueda, virrey de Cataluña y de Sicilia, y defensor de Messina en 1599.

32. Monreal, unos pocos quilómetros al sur de Palermo. Aquí también estuvo el capitán Alonso de Contreras, de cuyas excelencias habla en su Vida del capitán Contreras (1988, 156-167).

33. Actual Trápani, al suroeste de Sicilia. 
ro, y para ello nos ayudó otro que había venido en la barca que era natural de la dicha ciudad y nos prometía su casa y lo más necesario de aquí a que hallásemos embarcación, con esto nos animamos y me despedí del sobrino del arzobispo, que hizo que el mayordomo me diese sesenta reales para ayuda (Galán 2001, 160).

Gracias a este fragmento es posible observar cómo Palermo se había convertido en un lugar de acogida de cautivos. Ejemplo de ello son Diego Galán o los ocho hombres que habían logrado huir de manos enemigas, sin que sepamos ni sus nombres ni el lugar de donde venían ni su origen, excepto de un portugués de Lisboa con quien Diego Galán, había compartido la falta de libertad y con quien se embarcaría después rumbo a España.

En lo que a Sosa respecta, también se ha especulado con la idea de que pudiera haber contado en primera persona o incluso entregado en mano su manuscrito autógrafo a Diego de Haedo, con el fin de que lo publicara bajo su responsabilidad autorial ${ }^{34}$. Es más, se ha creído incluso que durante los casi dos años que coincidieron en Agrigento, Sosa podría haber hecho uso de la rica biblioteca personal del obispo para completar aquellas secciones más eruditas de su libro, especialmente las dos primeras, la Topographia o descripción de Argel y sus habitadores y costumbres, y el Epitome de los reyes de Argel, en donde hay una abundancia de citas procedentes de obras clásicas y contemporáneas del autor, de las que habría carecido obviamente en su prisión argelina.

Para justificar esta hipótesis, se ha tratado de exponer una serie de causas que habrían motivado la dura decisión de delegar en otra persona una obra que tanto esfuerzo y trabajo le había costado. Por un lado, cabría la posibilidad de que Sosa -de quien no hay constancia de que tuviera la intención de publicar su libro- se la hubiese entregado voluntariamente al obispo temiendo cercana su muerte. Por otro, la principal motivación habría que buscarla en el propio prestigio del portugués, que se hallaba por los suelos como consecuencia de los últimos escándalos personales, que habrían sido un obstáculo a la hora de intentar llevar a la imprenta su obra firmada con su nombre, puesto que las autoridades eclesiásticas de la época debían estar al tanto de su vida disoluta y tan poco ejemplar (Garcés 2011, 69). Los brazos de la inquisición española eran muy largos y la aparición de una obra publicada con su nombre habría levantado las sospechas cuando se hubiese procedido a solicitar las pertinentes licencias eclesiásticas, obligatorias desde 1558 (Lucía Megías 1999).

De acuerdo siempre con esta teoría, a raíz de estas particulares circunstancias, los Haedo se habrían «apropiado» de la obra con la «sana» intención de darla a conocer a un público ansioso de novedades sobre la presencia cristiana en el norte de África. Además, dicha obra corría el riesgo de desaparecer para siempre.

34. Esta hipótesis fue levantada por Camamis (1977) y seguida después por Garcés (2005a; 2005b). En ella se dice que debió ser en algún momento indeterminado de 1581 cuando Sosa le habría hecho entrega de su manuscrito, supuestamente en una parada en Sicilia antes de poner rumbo a España. 
Sin embargo, a esta conjetura le fallan las fechas, ya que no se entiende bien que no pudiera salir bajo el nombre de su verdadero autor pues, finalmente, la obra no se llevó a la imprenta hasta 1604, un año en el que no solo Antonio de Sosa llevaba muerto dos décadas, sino que además el rey Felipe II, tal vez el principal opositor a que saliera nada en nombre de alguien que le había traicionado, había fenecido ya.

También existe la posibilidad de creer que la intención de los Haedo no fuera tan honesta como pudiéramos pensar en un principio. Es decir, otra hipótesis factible consistiría en que tanto el tío como el sobrino pudieron haber ocultado el nombre del verdadero autor de manera consciente, atribuyéndose un libro que, ya sea por el fallecimiento de Sosa o por pura vanidad intelectual, nadie iba a reclamar como suyo. Al fin y al cabo ellos -más exactamente el sobrino- fueron quienes habían dado forma impresa a un texto en borrón, «de manera que sin el trabajo y diligencia que en ellos he puesto, dándoles la última forma y essencia, no se podían imprimir, ni sacar a luz». Y si uno echa un vistazo a la edición de 1612, solo encontrará a un tal «doctor Sosa» como un interlocutor más de los tres diálogos situados al final de la obra, pero ni rastro en el resto del libro de ninguna afirmación o comentario que pudiera dar pie a que alguien dudara de la autoría, al margen de comentarios personales de Sosa diseminados a lo largo de sus intervenciones que tienen que ver con su quehacer diario en su cautiverio. Una vaguedad intencionada, puesto que solo aquellos que hubieran estado en Argel y que aún estuvieran vivos podían conocer la verdad ${ }^{35}$.

En lo que se refiere a la obra en sí, a juzgar por los tiempos transcurridos entre los distintos textos preliminares, el proceso de edición tuvo que ser bastante complejo. La licencia del superior del general de San Benito, el maestro fr. Antonio Cornejo, data del 6 de octubre de 1604, en San Benito el Real de Valladolid; la carta-dedicatoria, como hemos dicho, está fechada en Frómista el día de Navidad de 1605; casi tres años después llegó de Madrid la aprobación de Antonio de Herrera, en concreto el 18 de octubre de 1608; por su parte, la licencia del rey con una duración de diez años aparece firmada en El Pardo el 18 de febrero de 1610; mientras que la fe de erratas y la tasa de Miguel de Ondarça Zavala pertenecen al 3 de junio y al 19 de octubre del mismo año, respectivamente. Por lo tanto, desde que se entregó el original a la imprenta, hacia la segunda mitad del año 1604, hasta que salió a la luz en 1612, en los talleres pucelanos de Diego Fernández de Córdoba y Oviedo, a costa del mercader de libros Antonio Coello, transcurrieron alrededor de ocho años. Unos tiempos nada habituales que nos hablan de la dificultad y vicisitudes que debió afrontar el sobri-

35. A este respecto, es una lástima no haber conocido la opinión de Miguel de Cervantes sobre este asunto, ya que él había convivido con todos y cada uno de los interlocutores mencionados en el libro y creemos que no hubiese visto con buenos ojos semejante robo intelectual. Es raro, además, que, publicada en la ciudad vallisoletana, donde había vivido durante algunos años, nadie le hiciera llegar a sus manos un ejemplar de la Topographia con información sobre un lugar que tan bien conocía y en la que, además, se le hacía una breve semblanza, la primera de las decenas que vendrían después. También es verdad que no conocemos el contenido de la biblioteca de Cervantes. 
no Haedo para conseguir su objetivo, tal vez porque a la hora de su salida al mercado ofrecía una historia de un lugar y de unas circunstancias de finales del XVI que nada tenían que ver con las de primeros del XVII. En cuanto a su impresión, gracias a una comparación de unos pocos ejemplares de la edición de 1612, es posible afirmar que existen dos estados diferentes de la misma edición con variantes tipográficas en las hojas con signatura A1 y A2 y con una diferente viñeta con escudo y dos putti en lugar de dos águilas y cornucopias ${ }^{36}$.

A partir de su puesta a la venta, los sucesivos editores y traductores del libro hasta mediado el siglo XX no pusieron casi nunca en duda su autoría. Así, por ejemplo, en Francia el padre trinitario Pierre Dan (1649), Monnereau y Berbrugger (1870-1871), o Grammont (1881) ${ }^{37}$, en sus traducciones parciales del texto al francés, Ferdinand Denis, en la Nouvelle biographie générale (1858), y en Inglaterra Joseph Morgan con su versión inglesa (1728-1729; $1731)^{38}$, todos hablaban de Diego de Haedo como autor de la obra, pero el sobrino, no el tío. El problema radicaba en que un texto de este calibre, tan detallista y tan descriptivo en lo que se refiere a experiencias personales y a la vida cotidiana de Argel, a sus costumbres o a sus gentes, solo podía haber sido escrito por alguien que hubiera vivido allí en primera persona, es decir, por un testigo directo de los hechos narrados, especialmente entre los años 1577 y 1581 . Y la biografía del obispo Diego de Haedo carecía de datos que le pudiesen vincular a la ciudad de Argel, a pesar de que hubo varios intentos que así lo trataron de demostrar. El primero de estos investigadores en especular con esta idea, aunque de manera conjetural y sin aportar documentación alguna, fue Denis, quien habla de la posibilidad de que Haedo o bien «alla sur les lieux» o bien «obtint des mémoires qui lui furent comuniqués par des religieux trinitaires» (Denis 1858, 51). Quien sí ofreció, supuestamente, apoyos documentales fue Grammont, que recogió el descubrimiento de un manuscrito por parte del padre Dan titulado Les illustres captifs, que se hallaba

36. Véanse, por ejemplo, los dos ejemplares conservados en la Biblioteca de Castilla-La Mancha, con signatura 4-8056 y $4-8057$.

37. Traducción francesa del Epitome de los reyes de Argel. Alude al artículo de Denis (1858), incluido en la Biographie générale y dedicado a Diego de Haedo, mediante el cual sospechaba que el autor debía haber hablado de visu. Y como refuerzo a su teoría, venía a añadirse el descubrimiento de un manuscrito por parte del padre Dan titulado Les illustres captifs, que se hallaba en la Bibliothèque Mazarine, n. 1919. Dentro del libro II que versa sobre Des chrétiens pris en mer par les infidèles musulmans, en el capítulo XII se recoge la biografía de Fray Diego de Haedo, «abbé de Fromesta», en Dan (1884) y Providence (1892).

38. Vol. 1, p. xxvii: «Nor am I a little indebted to F. Diego de Haedo, Abbot of Fromesta, whom I frequently mention. He wrote a circumstantial, and not contemptible Hiftory of Algiers; which he brings down to near the Conclusion of the fixteenth Century. But, excepting a few good Passages and Remarks, which I, occasionally, pick out, his three tedious Dialogues, in particular, concerning Captivity, Martyrs, and Morabboths, or Mahometan Santons, are filly enough, replete with nauseous Cant, and, in many Cases, insufferably partial. I am most his Debtor in the Succession of the Bashas, \&c.»; p. xxviii: «When I first thought of writing this Hiftory, my Design was to have taken Haedo and Him for my Ground-Work; out of which two imperfect Performances, with convenient Improvements and Corrections, some Book-sellers would have had me compile a regular History; but would have cramped me up to a moderate Volume in Octavo. But I knowing I had abundantly more to say, and very much to the Purpose». 
en la Bibliothèque Mazarine, bajo la signatura n. 1919. Dentro del libro II, que versa sobre Des chrestiens pris en mer par les Infidesles Musulmans, en el capítulo XII se recoge la biografía de Fray Diego de Haedo, «abbé de Fromesta», donde se afirma que este había permanecido cautivo en Argel entre 1578 y 1581 (Dan 1884) ${ }^{39}$. Sin embargo, estos datos se basaban en la vida que el padre Dan había elaborado a partir del propio texto de la Topographia, de modo que interpretó su contenido en clave biográfica.

En España la obra no despertó mucho interés hasta las primeras décadas del siglo XX, momento en el cual comenzó a dudarse de la tradicional autoría que se le venía otorgando por parte de estudiosos extranjeros, con alguna importante excepción como la del editor Ignacio Bauer y Landauer, que publicó el texto completo en tres volúmenes bajo el nombre de Diego de Haedo (1927a, 1927b, 1929a, 1929b y 1929c). En 1902 ya Cristóbal Pérez Pastor ${ }^{40}$ sugería la posibilidad de que Antonio de Sosa hubiese contribuido en la redacción de la obra, una teoría que sería apoyada más adelante por Luis Astrana Marín (1951, 96-105), para quien Sosa había sido el autor material de los tres diálogos, mientras que Georges Camamis, en su clásico Estudio sobre el cautiverio en el Siglo de Oro (1977, 124-150), aseguraba que Sosa lo era de la obra completa, afirmación esta asumida, entre otros, por Emilio Sola y José María Parreño (Sosa 1990b; Parreño 1990; Sola 1988 y 1990), Mounir Salah (1992) o, más recientemente, Galarreta-Aima (2015).

Desde entonces, casi nadie ha vuelto a poner en duda la atribución a Sosa, a excepción de Daniel Eisenberg (1996) -que llegó a atribuírsela inesperadamente al mismo Cervantes-, si bien es verdad que estudios posteriores de Marín Cepeda y, muy especialmente, de Garcés, han sido fundamentales para tratar de afinar todavía más en lo que respecta a la biografía y al grado de intervención de Sosa en la Topographia. En el caso particular de la primera, hemos de mencionar el hallazgo en Simancas de dos memoriales y tres presentaciones que atañen a Antonio de Sosa, todos ellos mencionados en líneas precedentes, que aportan novedades biográficas tanto sobre su trayectoria eclesiástica como sobre las circunstancias en que se llevó a cabo su rescate, aparte de que situaba la muerte de Sosa antes del 10 de agosto de $1588^{41}$. En cuanto a la segunda, cuyos trabajos sobre la vida y obra del eclesiástico portugués han supuesto un avance fundamental en su mejor conocimiento, cabe

39. «Je ne scay quelle fatale rencontre il tomba entre les mains des pirates d'Alger en l'annee mil cinq cens septante huit, et fut mené en captivité par ces Barbares, ou il souffrit beaucoup de miseres et d'injures de ces infames Mahometans, qui font gloire de leur cruauté à l'egard des Chrestiens qu'ils tiennent sous leur tyranie» (Dan 1884, 9-10; 40-41). El manuscrito completo se publicó unos años después en Providence (1892, I, 203-204).

40. «El doctor Antonio de Sosa, clérigo grande amigo de Cervantes, cautivado en 1577 y rescatado en 1581, autor de este Memorial y de los apuntamientos que sirvieron al Arzobispo Haedo para escribir la Historia general de Argel» (Pérez Pastor 1897, 235).

41. Simancas. AGS, S.P. (Secretarías Provinciales), libro 945, fol. 133v. Presentación a su favor [de Jerónimo Sancho] para el Deanato de la Iglesia mayor de Agrigento, de Real Patronato, que ha vacado por muerte de D. Antonio de Sossa, San Lorenzo, 10 de agosto de 1588. Véase Marín Cepeda (2010). 
destacar los muchos documentos que ha ido desempolvando del olvido gracias a su infatigable labor en archivos de todo el mundo. Ahí están su Cervantes en Argel: historia de un cautivo (2005b), así como su An early Modern Dialogue with Islam. Antonio de Sosa's Topography of Algiers (2011), en colaboración este último con Diana de Armas Wilson, que han arrojado nueva luz sobre la figura de este importante escritor del Siglo de Oro ${ }^{42}$. Tal vez su mayor contribución haya consistido en la investigación en torno a la vida de Sosa, su rescate y sus escándalos personales - la apostasía y el concubinatoque condujeron a la ira regia de Felipe II, así como la fecha definitiva de su fallecimiento en 1587. Unos hallazgos todos ellos que han servido para iluminar y comprender mucho mejor pasajes de este fascinante texto ${ }^{43}$.

Gracias, por tanto, a estos magníficos trabajos, hoy día es posible afirmar que la Topographia e historia general de Argel fue obra de tres personas: Antonio de Sosa, que habría elaborado un borrón del libro; el arzobispo Diego de Haedo, encargado de la recopilación de relatos de excautivos que probablemente sirvieron para enriquecer el texto original del portugués, añadiendo, entre otras cosas, aquellos hechos que van de 1587, año de la muerte de Sosa, a 1596, último que aparece mencionado en el libro; y, finalmente, el abad Diego de Haedo, encargado de pasar a limpio y dar forma al «borrón» que su tío le había entregado, así como de editarlo, sin descartar que pudiera haber sido él quien hubiese incorporado los añadidos de la obra.

A pesar de estos importantes avances, relacionados todos ellos con aspectos exclusivamente biográficos de Antonio de Sosa, y no de su obra, era necesario un documento como el que vamos a presentar a continuación que, cotejado con la Topographia, aportase datos fehacientes e inequívocos de que solo Antonio de Sosa podía estar detrás de la elaboración de dicha obra. Un documento que había pasado desapercibido para la mayor parte de los investigadores desde que el arabista Pascual de Gayangos lo consignara, por primera vez, en 1881, en su famoso Catalogue of Spanish manuscripts in the Spanish Language in the British Museum, tal vez porque su nombre aparecía escrito con una errata y no era fácilmente identificable, como se puede ver más abajo. Nos estamos refiriendo al manuscrito de la British Library de Londres, con signatura Add. 28366, que recoge un conjunto de «Papers relating to military affairs, 1565-83. The original Spanish title (now misplaced at fol. 295) was "Estado y Guerra Diversos desde el año 1570 hasta el de 1582= Vistos del año 1583= Hespaña; Milicia y Armar [sic] del Reyno"». Entre ellos figura, bajo el número 53 , dentro de los folios $148 \mathrm{r}-151 \mathrm{v}$, el siguiente texto:

Número de los baxeles de remo que [h] ay en Argel con los nombres de sus patrones y arraezes, los quales todo el año, invierno y verano, andan en corso sin parar, y arruynan la Christiandad; y de las personas que han lleuado captiuas al mismo Argel desde $1^{\circ}$ de Abril de 1577 hasta onze de

42. Al parecer, está preparando la traducción del resto de la obra de la Topographia, que deberá salir en breve.

43. Un resumen de la vida de Sosa también se puede consultar en Garcés (2017). 
Agosto de 1578. Enbiola el Doctor Antonio de Sora [sic], sacerdote captivo. Holog. f. 148 (Gayangos 1881, 773).

En honor de la verdad, el primero en llamar la atención sobre este documento fue el investigador Herrero García, quien aludía a él en una breve nota explicativa sobre el pirata argelino Morato Arráez que incluyó en la Revista de Filología Española, en 1926, como complemento y ampliación del estudio sobre el mismo tema que había publicado un año antes en el Homenaje ofrecido a $D$. Ramón Menéndez Pidal (Herrero García 1925). En aquel trabajo especulaba con la posibilidad de que hubiera sido el conde de Aytona ${ }^{44}$ el autor de la copia de dicho documento dirigido al Consejo de Guerra, a juzgar por su letra, igual a la de otras copias atribuidas a este noble insertas en el manuscrito Add. 28373 de la misma institución. Además, llegaba a ofrecer una parte de la transcripción del documento, especialmente lo relativo al personaje objeto de su estudio.

Muchos años más tarde, Mounir Salah (1992, 378-379, nota 386), sin conocer el trabajo de Herrero García y citando a Gayangos, apuntaba en su tesis doctoral, en una nota a pie de página, la existencia sin más de este documento. Sin embargo, no llegó a consultar nunca su contenido, ya que, de haberlo hecho, habría sacado conclusiones aún más irrefutables sobre la atribución de la Topographia a Antonio de Sosa, principal objeto de su estudio.

El sobrescrito del documento en cuestión se titula «Relación del número de vaxeles que al presente hay en Argel y andan en corso todo el año arruinando la Cristiandad, y de las personas que han llevado captivas al mismo Argel desde primero de abril de 1577 hasta onze de agosto 1578», y, aparte de indicar un número «25» que parece aludir a una secuencia de documentos enviados, probablemente, al mismo destinatario anónimo, se dice que «recibióse en octu[bre] 1578». Esto quiere decir que tardó aproximadamente dos meses desde que se acabó de redactar hasta que llegó a su receptor.

Sobre el autor de esta relación de avisos no hay ninguna duda. En el mismo sobrescrito se informa de que fue enviada por «el doctor Antonio de Sosa, sacerdote cautivo». Por lo tanto, este documento no es un autógrafo, pero sí una copia muy buena realizada por un secretario o un copista muy diestro, que nos informa al mismo tiempo de que su contenido interesaba mucho a su hipotético destinatario. Quizás la suposición de Herrero García en relación al conde de Aytona, capitán general de Cataluña, como autor de esta copia, pueda tenerse en cuenta ahora, aunque nos faltaría realizar el cotejo con el códice londinense que cita para sacar algunas conclusiones más definitivas.

La letra original de Sosa es fácil contrastarla con el documento que estamos dando a conocer y darnos cuenta de que no salió de su mano, ya que existen hasta tres autógrafos suyos repartidos en distintas bibliotecas. El pri-

44. Francisco de Moncada y Folch de Cardona (Mequinenza, 9 de octubre de 1532 -Valencia, 12 de noviembre de 1594) fue un noble y hombre de estado español, señor de las baronías de Serós, Mequinenza, Soses y Chiva. Desde 1574 por compra, era también conde de Osona y vizconde de Cabrera y Bas. Fue lugarteniente general de Cataluña entre 1580 y 1581, y virrey y capitán general de Valencia entre 1581 y 1594. Sobre este personaje, véase Mateu Ibars (1963). 
mero corresponde a la última declaración que, el 21 de octubre de 1580, incluyó él mismo en la Información hecha en Argel a solicitud de Miguel de Cervantes Saavedra acerca de los servicios y padecimientos prestados y sufridos por él mismo, que se conserva en Sevilla, en el Archivo General de Indias bajo la signatura Patronato 253, R.145; el segundo es una carta, escrita en Madrid con fecha del 23 de febrero de 1582, firmada por Sosa y el capitán Juan de Bolaños y dirigida al secretario de Felipe II, Mateo Vázquez, que se puede consultar en el Instituto Valencia de Don Juan de Madrid y que fue descubierta recientemente por Garcés (Garcés 2012; Sola y García 2012); y, por último, un tercer autógrafo escrito en Madrid, esta vez con fecha de 26 de agosto de 1582, conservado en la British Library con la signatura Add. 28342 (fols. 421r-421v), también dado a conocer hace poco por la anterior investigadora (Garcés 2011, 66). En los tres documentos, el eclesiástico portugués firma de la misma manera: «El Doctor Sosa», tal y como se muestra a continuación en una comparativa de las firmas:

a)

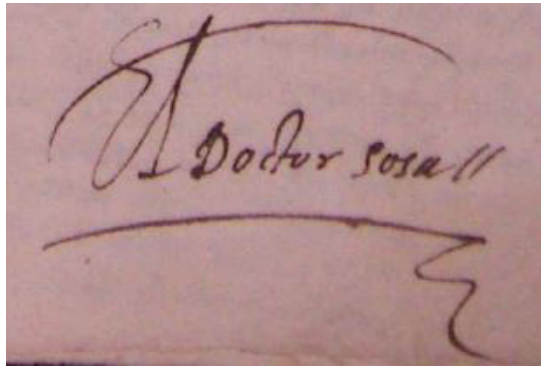

b)

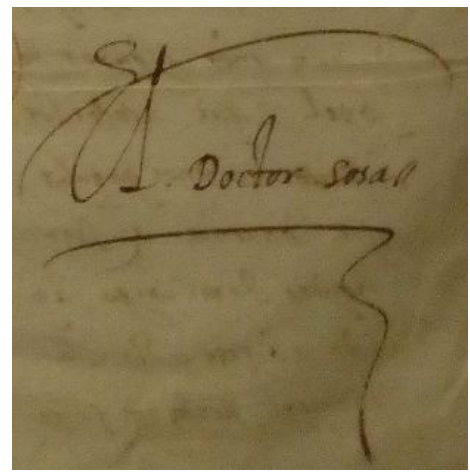

c)

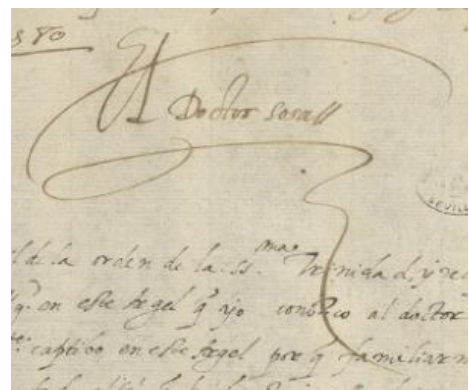

FIgURA 1. Firmas de Sosa:

a) Información de Argel. Argel, 21/10/1580. Sevilla, Archivo General de Indias, PATRONATO,253,R.1.

b) Madrid, 26/8/1582. Londres, British Library, Add. 28342.

c) Sosa. Madrid, 23/9/1582. Madrid, Instituto Valencia de Don Juan, envío 62, caja 2, fol. 26.

45. Este documento es posible consultarlo en el Portal de los Archivos Españoles (PARES). 
En cuanto al contenido del documento Add. $28366^{46}$, se articula en dos partes claramente diferenciadas. La primera es una relación bastante completa de los piratas, patrones y arraeces así como del número de bajeles de remo con que contaban cada uno de ellos y con los que solían asolar la cristiandad. Por su parte, la segunda consiste en una relación aún más exhaustiva del número de cautivos cristianos que los corsarios habían secuestrado desde el primero de abril de 1577 hasta el 11 de agosto de 1578. Informaciones todas ellas valiosísimas para conocer los entresijos de la ciudad argelina, de los corsarios y de los cautivos cristianos que llegaban a aquellas duras tierras.

En lo que se refiere a la primera parte, los datos que se ofrecen son los siguientes: el nombre de los patrones y arraeces, su cargo, si lo tienen, su condición social y religiosa, su procedencia y, por último, el número de barcos que posee cada uno así como su respectivo número de bancos. Al final de cada entrada se ha incluido un número romano en mayúsculas haciendo alusión al número de barcos de cada patrón, cuyo total se incluye al término de cada apartado, en el margen derecho, dando como resultado final un total de 82 embarcaciones.

Así, el primero y más importante en aparecer es Azán, «renegado de Uchalí, veneciano de nación, rey de Argel», en cuyo poder tenía cinco galeras, una de 28 bancos y cuatro de 25. El segundo en importancia era el renegado esclavón Arnaut Mamí, que era capitán de la mar de Argel y cabeza de los corsarios, quien poseía hasta dos bajeles de 22 y 23 bancos. De él se dice que era «crudelíssimo enemigo de los cristianos». El tercero, también con tres bajeles en su haber, de 22 bancos cada uno, era Dalí Mamí, renegado griego.

En cuanto al resto de los patrones incluidos en esta larga relación, solo poseen una embarcación cada uno, de los cuales podríamos destacar a Moret, «arráez que dizen el Grande, renegado esclavón», con una de 29 bancos; Morat, arráez, renegado español de Murcia más conocido por su apodo de Maltrapillo, con una de 20; Caurali, que era hijo de un renegado napolitano, con otra de 20; Marjamamí, renegado genovés, con una de 17; Azán, genovés, renegado del morabito, con una de 16; Mamí Gancho, renegado veneciano, con una de 22; o Caide Mahamet, el amo de Antonio de Sosa, quien era judío de nación, pero que se convirtió al cristianismo para finalmente ser turco, con una de 14.

Informa también de otras seis embarcaciones que se estaban construyendo en el atarazanal, propiedad de los siguientes corsarios: el rey Hazen; Cadí, arráez turco, capitán que fue de Biserta; Ferru, arráez renegado, genovés; Sinón, arráez turco; Jafe, arráez renegado, napolitano; y Morat, arráez el Grande, turco.

Además, añade a este número los 36 bergantines armados o fragatas de 10-12 bancos que estaban armando entre dos y tres patrones, los cuales hacían mucho más daño que los anteriores porque se escondían en las calas de las

46. En breve vamos a publicar el texto completo de Antonio de Sosa. 
marinas sin posibilidad de ser descubiertos y cautivaban a multitud de cristianos cuando menos se lo esperaban.

Pero no acaban ahí las cuentas. A todas estas embarcaciones suma otras seis galeotas de 20 bancos cada una, propiedad de turcos mercaderes, que, aparte de servir para enviar mercancías a Trípoli, Túnez, Bona, Biserta o Tetuán, solían ser utilizadas para armarlas y enviarlas en corso junto a los demás corsarios.

En resumen, todos estos bajeles, desde el primero de abril de 1577, cuando tomaron la galera San Pablo de Malta, hasta el 11 de agosto de 1578, momento de redacción del presente documento, cautivaron a 2501 personas, entre hombres, mujeres, mozos y muchachos.

Fuera de este número nada desdeñable quedaban aquellos cristianos que los corsarios habían vendido o cautivado en otros lugares de Berbería, como Túnez, Biserta, Susa o Bona, en aguas del Estrecho, como Tetuán, Alarache o Salle, en la costa levantina o en la italiana, como Cerdeña, Sicilia o Nápoles. La cifra exacta le resultó difícil de hallarla debido a la complicada situación en que se debía encontrar.

En estas estadísticas tampoco entraban otros tantos navíos y bajeles de remo que tomaron durante esos 16 meses, «que no lo he podido saber menudamente porque o los queman o dan fondo y anegan, o los dexan desamparados, y pocos traen a este Argel», ni las muchas riquezas que habían atesorado, porque eran infinitas.

Por último, alude a un tema no menos importante y de gran actualidad en aquel momento, como es el de los renegados ${ }^{47}$. Asevera que no era posible conocer el número exacto de este grupo, en el que había «griegos, rossos, esclavones, italianos, franceses, españoles y todas las otras naciones», aunque de la Casa del Rey sí que ofrece una cifra estimada de más de 4000, la mayoría grandes conocedores de las costas cristianas y, por lo tanto, «esta es sola la fuerça deste Argel». No obstante, muchos de ellos se pasaban el tiempo recorriendo la Berbería tratando de recoger los altos tributos que habían impuesto a los moros, con quienes no dudaban en usar la fuerza para someterlos.

Ahora bien, si comparamos el contenido y la estructura de estas informaciones con el capítulo 22 de la Topographia, titulado «Del número de los cosarios, de galeotas y de sus bajeles que había en Argel el año 1581», aparte de la similitud en el enunciado y en el contenido, nos daremos cuenta de inmediato no solo de que figuran casi los mismos patrones y arraeces, sino también de cómo se utiliza la misma disposición de la información, si bien es cierto que estos datos están actualizados a la fecha indicada, es decir, de 1581. Véase a conti-

47. Sobre los renegados, sigue siendo fundamental el trabajo de Bartolomé Bennassar y Lucile Bennassar (1989). En esta obra, alude precisamente a este listado de la Topographia en las páginas 413416, en donde hace una recopilación de los datos expuestos: «Son, pues, seis genoveses, dos venecianos, dos albaneses, tres griegos, dos españoles, un francés, un húngaro, un siciliano, un napolitano, un calabrés, un corso y tres hijos de renegados: veinticuatro arráeces de origen cristiano, procedentes de casi toda la Europa mediterránea, a los que se suman diez 'turcos' y un judío. Poseen una flota de treinta y seis galeotas a las que hay que añadir, como hace Haedo, las fragatas (o bergantines), navíos de ocho a trece bancos, muy numerosas en Argel, en manos de turcos, de moriscos españoles o de renegados». 
nuación un cuadro comparativo con una selección de contenidos entre ambos textos para comprobar las múltiples semejanzas que existen:

\begin{tabular}{|c|c|c|c|c|c|}
\hline \multicolumn{3}{|c|}{ Haedo 1612, fols. 18r-18v; Haedo 1927a, $89-90$} & \multicolumn{3}{|c|}{ British Library Add. 28366, 149r-150v } \\
\hline $\begin{array}{l}\text { PATRONES Y } \\
\text { ARRAECES }\end{array}$ & $\begin{array}{l}\text { N. }{ }^{\circ} \mathrm{DE} \\
\text { BARCOS }\end{array}$ & $\begin{array}{l}\text { N. }{ }^{\circ} \text { DE } \\
\text { BANCOS }\end{array}$ & $\begin{array}{l}\text { PATRONES Y } \\
\text { ARRAECES }\end{array}$ & $\begin{array}{l}\text { N. }{ }^{\circ} \mathrm{DE} \\
\text { BARCOS }\end{array}$ & $\begin{array}{l}\text { N. }{ }^{\circ} \text { DE } \\
\text { BANCOS }\end{array}$ \\
\hline $\begin{array}{l}\text { Jafer, rey de Argel, } \\
\text { renegado húngaro }\end{array}$ & 1 & 24 & $\begin{array}{l}\text { Azán, renegado de } \\
\text { Uchalí, } \\
\text { veneciano. Rey de } \\
\text { Argel }\end{array}$ & 5 galeras & $\begin{array}{l}28(1) \\
25(4)\end{array}$ \\
\hline $\begin{array}{l}\text { Mamí Arnaut, } \\
\text { capitán de la mar }\end{array}$ & 1 & 22 & $\begin{array}{c}\text { Arnaut Mamí, } \\
\text { capitán de la mar } \\
\text { de Argel }\end{array}$ & 2 bajeles & $\begin{array}{l}23 \\
22\end{array}$ \\
\hline $\begin{array}{c}\text { Morat francés, } \\
\text { renegado del mismo } \\
\text { capitán }\end{array}$ & 1 & 22 & $\mathrm{x}$ & $\mathrm{x}$ & $\mathrm{x}$ \\
\hline $\begin{array}{l}\text { Dalí Mamí, } \\
\text { renegado griego }\end{array}$ & 1 & 22 & $\begin{array}{l}\text { Dalí Mamí, } \\
\text { renegado griego }\end{array}$ & 3 bajeles & 22 \\
\hline $\begin{array}{c}\text { Morato Raez, el } \\
\text { Grande, renegado } \\
\text { albanés }\end{array}$ & 2 & 24 & $\begin{array}{l}\text { Moret, arráez el } \\
\text { Grande, renegado } \\
\text { esclavón arnaut }\end{array}$ & 1 & 29 \\
\hline Iza Raez, turco & 1 & 18 & Iça, arráez turco & 1 & 18 \\
\hline $\begin{array}{c}\text { Morato Raez el } \\
\text { Pequeño, renegado } \\
\text { griego }\end{array}$ & 1 & 18 & $\begin{array}{l}\text { Morat, arráez el } \\
\text { Pequeño, renegado } \\
\text { griego }\end{array}$ & 1 & 18 \\
\hline $\begin{array}{l}\text { Asán, ginovés, } \\
\text { renegado del } \\
\text { morabuto }\end{array}$ & 1 & 18 & $\begin{array}{c}\text { Azán, genovés, } \\
\text { renegado del } \\
\text { morabito }\end{array}$ & 1 & 16 \\
\hline Mamixa, turco & 1 & 18 & Mamija, turco & 1 & 18 \\
\hline $\begin{array}{c}\text { El Caide Mahamed, } \\
\text { judío }\end{array}$ & 1 & 15 & $\begin{array}{l}\text { Caide Mahamet, } \\
\text { judío, cristiano y } \\
\text { turco }\end{array}$ & 1 & 14 \\
\hline $\begin{array}{l}\text { Asán Ginovés, } \\
\text { renegado ginovés }\end{array}$ & 1 & 15 & $\begin{array}{l}\text { Azán, arráez, otro } \\
\text { genovés renegado }\end{array}$ & 1 & 15 \\
\hline $\begin{array}{l}\text { Caur Alí, hijo de } \\
\text { renegado }\end{array}$ & 1 & 20 & $\begin{array}{c}\text { Caurali, hijo de un } \\
\text { renegado napolitano }\end{array}$ & 1 & 20 \\
\hline $\begin{array}{l}\text { Jafer, renegado } \\
\text { genovés }\end{array}$ & 1 & 20 & $\begin{array}{c}\text { Jafer, arráez } \\
\text { renegado genovés }\end{array}$ & 1 & 27 \\
\hline $\mathrm{x}$ & $\mathrm{x}$ & $\mathrm{x}$ & $\begin{array}{c}\text { Barcos en ataraça- } \\
\text { nal: en construcción }\end{array}$ & & \\
\hline $\mathrm{x}$ & $\mathrm{x}$ & $\mathrm{x}$ & Rey Hazen & 1 & 24 \\
\hline $\mathrm{x}$ & $\mathrm{x}$ & $\mathrm{x}$ & Cadí, arráez turco & 1 & 22 \\
\hline $\mathrm{x}$ & $\mathrm{x}$ & $\mathrm{x}$ & $\begin{array}{l}\text { Bergantines } \\
\text { armados }\end{array}$ & 36 & $10-12$ \\
\hline $\mathrm{x}$ & $\mathrm{x}$ & $\mathrm{x}$ & $\begin{array}{l}\text { Galeotas de turcos } \\
\text { mercaderes }\end{array}$ & 6 & 20 \\
\hline
\end{tabular}


Si analizamos más en detalle estos datos, podemos sacar algunas conclusiones interesantes. Al margen de que el manuscrito aluda a una fecha tres años anterior a la del texto de la Topographia, que se refiere al año 1581, muchos de los datos ofrecidos en ambos son prácticamente los mismos. Así, por ejemplo, Caur Alí, hijo de un renegado napolitano, o Mamí, renegado corso, seguían poseyendo un barco de 20 bancos cada uno en 1581; los turcos Iza Raez, Mamixa y el renegado griego Morato Raez el Pequeño mantenían, por su parte, una embarcación de 18 bancos; o el renegado genovés Asán, que seguía teniendo un barco de 15 bancos.

En algunos casos particulares, ora por error ora porque hubiese cambiado de embarcación, hay una pequeña variación en el número de bancos, de tal manera que el judío Caide Mahamet pasó de una de 14 bancos a otra de 15 en 1581; lo mismo sucede con Jafer, arráez, renegado genovés, que pasó de una de 27 a una de 20.

En cuanto a varios de los personajes más poderosos de Argel, es posible ver cómo Arnaut Mamí, capitán de la mar, contaba en 1581 con un único barco de 22 bancos, frente a los dos de 23 y 22 que tenía en 1578; o el renegado griego Dalí Mamí, que de tres embarcaciones pasó a solo una en 1581; mientras que en el lado opuesto vemos al renegado albanés Morat Raez el Grande, que de un barco de 29 bancos pasó a tener dos de 24 más tarde.

Por último, observamos cómo el ahora rey de Argel, el renegado húngaro Jafer, ostentaba una única embarcación de 24 bancos, frente a las cinco galeras que poseía el rey Azán en 1578.

De igual modo, si leemos con atención el capítulo 23 de la Topographia titulado «De los cosarios de bergantines de Argel a que llaman fragatas», veremos cómo buena parte de su contenido amplía algunos aspectos tratados en el manuscrito, aparte de que usa un léxico y unas expresiones muy parecidas, si no iguales. En este último leemos lo siguiente:

Vergantines armados que aquí llaman fragatas, que son diez hasta doze bancos, y que arman dos y tres padrones; contribuyendo sus partes, son 36, y estos hazen más daño porque se cubren fácilmente con las puntas y se esconden en las calas que están por las marinas, y continuamente invierno $y$ verano vienen cargados de cristianos: XXXVI.

[...] De renegados griegos, rossos, esclavones, italianos, franceses, españoles y todas las otras naciones no se puede saber el número cierto d'ellos. De Casa del Rey he sabido que passan de 4000, los más d'ellos pláticos en todas las costas de la Cristiandad, y esta es sola la fuerça deste Argel, porque todos los demás son gente canalla, vilíssima, y aun d'estos la mitad y más anda ordinariamente derramada por esta Bervería cogiendo de los moros los tributos con las armas en la mano, y no están en Argel (la cursiva es nuestra).

Mientras que en el texto impreso leemos lo siguiente:

Otros cosarios hay de fragatas, que son bergantines, de ocho hasta trece bancos, y ordinariamente se hacen estos bajeles en Sargel, que está, 
como dijimos, veinte leguas, que son sesenta millas de Argel para Poniente, adonde hay muy gran copia de madera para hacerlos. Los maestros dellos son todos moriscos de Granada, Valencia y Aragón, de los cuales está todo aquel lugar lleno y poblado. Estos son (por la mayor parte) los arraeces dellos, porque, como son todos nacidos en España, son muy pláticos en sus puertos, marinas y costas. También hay muchos turcos y renegados que son arraeces destas fragatas, porque tanto que un levente y hombre de mar se halla con 150 y con 200 escudos, a la hora se juntan con otros, y todos a común espensa hacen un bergantín y le arman de todo lo necesario, y con él van por todas las partes haciendo grandísimos daños, y particularmente los moriscos de Sargel, como son tan pláticos en la costa de España, y en ella tienen todos parientes, hermanos y amigos. Llegados que son en alguna parte, entierran el bergantín con todo el pararejo ${ }^{48}$ debajo la arena, en una fosa y hoyo grande; y entrando en la tierra en hábito cristianesco, y hablando muy bien español, y siendo muy bien recogidos en lugares de otros moriscos, atajan fácilmente los caminos, principalmente de noche, y maniatando todos los cristianos que topan los traen a la marina y desenterrando el bergantín, se vuelven con ellos, muy a placer, a sus casas. Tienen también otra cosa: que como estos bajeles son pequeños, fácilmente se asconden en alguna cala o punta do no son vistos, y engañando desta manera las guardias que están en las torres de las marinas, salen en mitad del día a los caminos en hábito de cristianos, y roban, $y$ toman de continuo mucha gente, y por esta causa estos bajeles sin duda son los que más daño hacen en la cristiandad, porque navegan de continuo todo el verano y invierno sin cesar ni reposar. Y como los robos que con ellos hacen son tan grandes, fácilmente suben los arraeces dellos a ser en poco tiempo arraeces de galeotas, y así, ordinariamente, de aquí comienzan y tienen todos su principio. Los que bogan en estos bajeles son, ordinariamente, renegados, o turcos, o moros, los cuales todos van a la parte así en el gasto como en la ganancia que se hace, y todos llevan sus armas, arcabuces o buenos arcos o flechas con que pelean, tanto que dejan de las manos los remos. También suelen alquilar algunos bagarinos, que son los moros que dijimos que vivían de bogar en los bajeles de buenas boyas. El número destos bergantines o fragatas no es cierto, ordinariamente, entre los que se hacen en Argel, y en Sargel habrá como veinte o veinticinco. Los usos y costumbre (sic) destos cosarios son los mismos que de los otros de las galeotas (Haedo 1927a, 91-92) (la cursiva es nuestra).

En cuanto al contenido de la segunda parte del documento que estamos dando a conocer, la información se distribuye de la siguiente manera: el mes y día en el que tuvo lugar el acontecimiento, el número de embarcaciones turcas y el nombre de su patrón o patrones, el lugar donde se produjo el rapto de cristianos, y, por último, el número total de cristianos cautivados, que, como en el primer documento, se inserta en el margen derecho dando la suma total al final de cada página.

48. «El pararejo», según la edición de 1927a. En el original de 1612: «el aparejo». 
Además de poner de manifiesto el hecho de que Sosa empezó a tomar notas desde el mismo día en que fue capturado, el primero de abril de 1577, se nos ofrecen unos datos valiosísimos para conocer una cifra más o menos exacta de los cautivos cristianos que llegaron a tierras argelinas durante este período. La única lástima es no haber incluido la identidad de los cautivos para saber sus orígenes, edades y clase social a la que pertenecían, tal y como hacían los padres redentores cuando liberaban a los cautivos.

El período de mayor productividad por parte de los corsarios berberiscos fue la primavera de 1577, tiempo durante el cual, entre otros apresamientos, doce galeotas tomaron 290 cautivos de la galera San Pablo de Malta en la isla de San Pedro; Morato arráez el Grande apresó a 90 en Sicilia y Calabria; y una fragata tomó de las costas de España y Poniente hasta 17.

Por su parte, el invierno y primavera siguientes fueron todavía más fructíferos en lo que se refiere a la obtención de prisioneros cristianos. De ellos podríamos destacar los siguientes: el 15 de febrero, 9 galeotas secuestraron a lo largo de Cerdeña, Córcega, Sicilia, Calabria y Nápoles, un número indeterminado de cristianos que vendieron luego en Túnez, Biserta y Susa, dejando alrededor de 800, entre mujeres, mozos y muchachos, en Argel; el 8 de abril dos fragatas raptaron a 40 en Cerdeña y Córcega; el 3 de mayo Mamí Longo tomó a 145; y el 27 del mismo mes otras nueve galeotas, junto a dos galeras de Sicilia, tomaron en el golfo de Salerno hasta un total de 470 personas.

El verano de 1578 tampoco se dio mal desde el punto de vista de los cautiverios. Así, por ejemplo, el 5 de julio Mamí Gancho, Dalí Mamí y el arráez turco Isuf raptaron de Mallorca, Menorca, Ibiza y Barcelona 65 cautivos; por su parte, Azán, rey de Argel, que salió con 22 galeotas y fragatas, tomó también en Mallorca, Ibiza y Alicante 30, 60 y 120 personas, respectivamente.

El total de «ánimas» que los corsarios llevaron a Argel lo estimó, como se ha dicho anteriormente, en 2501. He aquí un resumen de los datos ofrecidos anteriormente:

\begin{tabular}{|c|c|c|c|}
\hline \multicolumn{4}{|c|}{ British Library Add. 28366, 149r-150v } \\
\hline FECHA & BARCOS DE CORSARIOS & LUGAR & N. $^{\circ}$ CAUTIVOS \\
\hline $1-4-1577$ & 12 galeotas & Isla de S. Pedro, Cerdeña & $\begin{array}{c}290 \\
\text { (galera S. Pablo) }\end{array}$ \\
\hline $16-5-1577$ & Morat Arráez el Grande & Sicilia y Calabria & 90 \\
\hline $15-6-1577$ & 1 galeota & Poniente, España & 20 \\
\hline $10-9-1577$ & 1 fragata & $\begin{array}{c}\text { Costa de España y } \\
\text { Poniente }\end{array}$ & 17 \\
\hline $15-2-1578$ & 9 galeotas & $\begin{array}{c}\text { Cerdeña, Córcega, Sicilia, } \\
\text { Calabria, Nápoles }\end{array}$ & 800 \\
\hline $3-5-1578$ & $\begin{array}{c}\text { Mamí Longo, renegado corso } \\
4 \text { fragatas }\end{array}$ & Córcega & 145 \\
\hline
\end{tabular}




\begin{tabular}{|c|c|c|c|}
\hline $18-5-1578$ & 9 galeotas & $\begin{array}{c}\text { Riberas de Sicilia y } \\
\text { Calabria } \\
\end{array}$ & 470 \\
\hline $25-6-1578$ & $\begin{array}{l}\text { Azán, arráez renegado } \\
\text { genovés y Azán, renegado } \\
\text { del morabito, genovés. } \\
2 \text { galeotas }\end{array}$ & Sicilia y Cerdeña & 60 \\
\hline $5-7-1578$ & $\begin{array}{c}\text { Mamí, gancho, renegado } \\
\text { veneciano, y Isuf, arráez } \\
\text { turco. } \\
2 \text { galeotas } \\
\end{array}$ & $\begin{array}{c}\text { Mallorca, Menorca, Ibiça, } \\
\text { Barcelona }\end{array}$ & 65 \\
\hline $11-8-1578$ & $\begin{array}{l}\text { Azán, renegado veneciano, } \\
\text { rey de Argel. } \\
22 \text { galeotas y } 4 \text { fragatas }\end{array}$ & Mallorca, Ibiça, Alicante & 210 \\
\hline
\end{tabular}

En este caso, es verdad que la comparación de estos datos con el texto de la Topographia no revela tanta proximidad, pero sí se hacen alusiones en esta última a las distintas campañas llevadas a cabo por los corsarios. Así, por ejemplo, se habla de que en la primavera de 1577 hubo operaciones muy exitosas, en clara referencia a la toma de la galera maltesa San Pablo, mientras que en el verano del mismo año todo fue al contrario, pudiendo calificarse de fracaso. Igualmente, hay noticias de otros dos importantes apresamientos por parte de los corsarios berberiscos. El primero realizado por Morat Arráez el 12 de mayo de 1578, que supuso la toma de la galera del duque de Terranova. El segundo, más importante si cabe, lo realizó el rey Hazán en la campaña que efectuó entre el 20 de julio de 1578 y el 11 de agosto de ese año en Mallorca, Ibiza y Valencia, donde secuestró a 180 cristianos.

En relación con el documento que acabamos de presentar, habría que referir también otro que, de acuerdo de nuevo con el catálogo de Gayangos (1881, 772), aparece en el mismo manuscrito londinense, entre los folios 120r y $121 \mathrm{v}$, y que, de acuerdo con su contenido («Relación y modelo de Argel; 1577 , f. 120»), podría adjudicarse a la paternidad de Antonio de Sosa por una serie de razones que vamos a exponer. Se trata de una misiva, probablemente acompañada de un mapa y de alguna otra aclaración no conservadas, en donde se describen un conjunto de lugares estratégicos encabezados por unas letras mayúsculas de la A a la Z (23 lugares) y por unos números del 10 al 17 (8 lugares), que harían referencia, sin duda, al desaparecido mapa ${ }^{49}$.

El sobrescrito lleva por título «Modelo de Argel»e indica la fecha de «1577», más una anotación cortada por la encuadernación del volumen que parece indicar lo siguiente: «Rel[aci]ón 31», supuestamente en alusión a una secuencia de documentos enviados de manera conjunta - o separada- y que guardaría relación con el número «25» del texto que hemos presentado con anterioridad, ya que, al parecer, la letra es la misma. Este hecho podría inducir a pensar en un conjunto de documentos de una misma temática -argelina- copiados todos por una sola persona - ¿por Francisco de Moncada y Cardona, conde de Aytona?- para un

49. Londres. British Library, Add. 28366, fols. 147r-148v. Modelo de Argel. 
mismo destinatario anónimo interesado en conocer los entresijos de uno de los centros de poder más importantes del norte de África.

Entre los sitios más llamativos de la ciudad destacan, por ejemplo, con la letra A, la alcazaba, que «está en lo más alto de la ciudad» y «tiene su artillería a todas partes»; con la B alude a la Casa del Rey, «donde habita de ordinario»; en la $\mathrm{C}$ ubica la mezquita mayor; en las E y F sitúa las casas que se hallaban sobre la muralla, donde «hazen cuerpo de guardia los geníçaros»; en la letra $\mathrm{G}$ se encontraba «la casa de la pólvora y municiones»; la $\mathrm{H}$ recoge un lugar estratégico para los cristianos, pues es donde se sitúa el baño, «donde están y se recogen todos los captivos»; con la $\mathrm{M}$ se alude al baluarte de la marina, que «tiene de ordinario como 14 pieças de artillería gruessa»; la $\mathrm{O}$ guarda relación con la torre de la «lanterna y fanal para [que] atinen de noche los bajeles al puerto»; el «magazén» corresponde a la $\mathrm{R}$, «donde guardan las velas y xarcias y otros adereços de las galeotas que se varan en la isla, aunque los remos los meten en la ciudad haziendo que cada captivo tenga c[uen]ta con el suyo y lo tenga a punto para cuando se le pidiere»; la $\mathrm{V}$ hace alusión al puerto, «donde podrán caber 30 galeotas, poco más o menos»; la Y y la Z hacen referencia al lugar de enterramiento de los reyes argelinos y a una mezquita de un morabito que llaman Cid Bonor, respectivamente; además, especifica que entre esta última «y el castillo de Luchalí dizen que hay agua ${ }^{50}$.

En cuanto a los números, con el 10 se refiere al castillo de Hazán Bajá, «que lo hizo después que el Emperador, nuestro señor, se retiró d'ella, en el mesmo lugar donde estuvo alojado. Es, creo, cuadrado, aunque por la parte de la montaña, por tener padrastros, tienen más levantada la fortificación para cubrir la plaça del castillo»; el 11 hace referencia al «castillo pentágono que hizo Mahamet Baxá, y llámanle la Estrella»; el 15 alude a la «puerta de la ciudad donde llegaron los cristianos y comendadores de san Juan cuando se hizo la última jornada»; mientras que el 17 correspondería al «baluarte de los renegados»».

El documento acaba informando sobre la cantidad de tiradores, jenízaros y gente de guerra que había allí: «Hay en la tierra 16 unidades [de] tiradores, gente de guerra, las 6 unidades [de] geníçaros mezclados con leventes, que son ya todos geníçaros por las passiones que havía entre ellos. Estos son los de guarnición, 3 unidades [de] cabailes y 7 unidades [de] gente de la tierra».

50. En la Topografia de Sosa se alude al morabito Cid Bonor en los siguientes términos: cap. XXVII, De los morabutos de Argel: «Fué un renegado cordobés que no ha mucho que murió, el cual vivió algunos años en la montaña más alta para Poniente, distante de Argel media legua, que tenía para esto (según es cosa muy notoria), grande mano, y llamábase ese Cidbornoz; hoy día es visitado su sepulcro (que está en la hermita do vivía), como de un grande y excelente varón» (Haedo 1927a, 103-107); nuevamente, en el capítulo 33 (De los exercicios de las mujeres de Argel y sus alhajas de casa) se vuelve a aludir a este mismo personaje y a su ermita: «Lo cuarto, en visitar las hermitas y los sepulcros de los morabutos, a los cuales ofrecen y llevan sus hijos, como en romería, porque los lunes visitan el sepulcro del morabuto Cid Jacob, que está en/ una peña junto a la mar, fuera de la puerta de Babaluete, a la fiumara. El de Cid Bornoz, renegado cordobés, que está en lo alto de la montaña, que allí luego está en una hermita en que vivió» (Haedo 1927a, 136-137). 
No obstante, al margen de todas estas referencias de lugares, a nosotros nos gustaría destacar especialmente dos de ellas porque son aquellas que nos hacen creer que el texto es del portugués Sosa. En concreto, las relativas a las letras $\mathrm{N}$ y X. En lo que a la primera se refiere, corresponde a la «puerta de la ciudad que llaman de la Marina o Muelle. En esta puerta tienen una figura de S. J[ua]n Baptista de mármol, como de dos tercias, colgado como en ignominia de la garganta con una soga y por medio del cuerpo con una cadena; y a los cristianos que passan por allí se lo enseñan por menosprecio».

Esta referencia tiene algunas semejanzas con lo que se narra en el capítulo 35 de la Topographia, que lleva por título «Miscelánea de algunas opiniones, costumbres, usos y observancias que tienen los turcos, moros y renegados de Argel». Aquí se habla del pecado que suponía para turcos y moros la adoración y veneración de imágenes, y cómo, en el mes de mayo de 1579, ante la acuciante sequía y hambruna que había en Argelia, aquellos realizaban procesiones a los sepulcros de los morabutos con el fin de mitigar sus consecuencias. Debido a lo infructífero de sus peticiones, al final los morabutos propusieron al rey de Argel que no solo impidiese a los cristianos decir misa, sino que también retirase las tres imágenes cristianas situadas en la puerta de la Marina, «las cuales los turcos allí tenían colgadas por los pies, con algunos escudos y rodelas cristianas, siendo aquel lugar y paso tan público y frecuentado de toda la gente, diciendo que estas dos cosas de cristianos causaban entonces tan gran falta de agua del cielo y tenían a Dios indignado» (Haedo 1927a, 159). Azán Bajá cumplió sus deseos de tal manera que, además de suspender cualquier tipo de celebración eucarística, ordenó hacer pedazos y quemar las tres imágenes. Estas habían sido tomadas en algunas galeras y correspondían, la primera, al Ángel santo, robada en la galera Santángel del duque de Terranova el 27 de abril de 1578, junto a la isla de Capri; la segunda, al apóstol san Pablo, obtenida en la galera homónima el primero de abril de 1577, muy cerca de Cerdeña; y la tercera y última, a san Juan Bautista, robada por el Uchalí en una de las galeras de Malta en 1570, al pie de la ciudad siciliana de Licata (Haedo 1927a, 159).

En cuanto a la segunda referencia, mucho más clara y que es nuestro principal argumento para otorgar la paternidad de este texto al eclesiástico Sosa, alude al

castillo que hizo Luchali. Es triangular, sitiado sobre peña, terraplenado todo. Tiene la entrada por lo alto d'él, subiendo por gradas. Este defiende la batería que por aquella parte se le puede dar a la tierra, que sería de mucho efecto. En las murallas d'este castillo está un cuerpo de un mártir que martirizó allí Luchalí cuando se hazía, haziéndolo enterrar bivo hasta la garganta. Este fue un moro natural de Argel y, siendo captivo en Orán, se quiso baptizar de su voluntad y haviendo servido muy bien a su amo, le dio libertad. Quísose venir a España y en el camino fue captivado de unas galeotas de Argel y llevado allá y reconocido y, advertido a sus padres cómo le traían, nunca quiso reconocellos [dizendo] que él era cristiano y era burlería todo cuanto le dezían. Llevándole ante Luchalí y amenazándole 
con muchas penas, no las estimó, diziendo que havía passado más Nuestro Señor por él y assí le mandó tapiar vivo en aquella obra que hazía hasta la garganta, y truxeron morabitos para que le persuadiessen y él los confundía y estuvo siempre constantíssimo hasta que un renegado le dio con un martillo en la cabeça y lo acabó y assí quedó allí. Plazerá a Nuestro Señor que, por los méritos d'este, se gane aquel castillo y lo demás y, tomado el castillo, se tiene por más fácil d'esta parte la batería y arremetida ${ }^{51}$.

A partir de esta extensa cita, es posible comprobar un vínculo evidente tanto con el contenido como con la estructura del relato 17 del Diálogo de los mártires. En él se nos cuenta precisamente la historia real sucedida entre Euch Alí y el moro cristiano Jerónimo. El caso es que este, siendo apenas un niño, fue hecho prisionero por los soldados cristianos de Orán en tierra de moros y vendido después al licenciado Juan Caro, vicario y general de la mencionada ciudad. Al cabo de un tiempo, el muchacho se hizo cristiano y tomó el nombre de Jerónimo. Más tarde, durante la peste que asoló la ciudad, algunos moros consiguieron huir de allí, llevándose consigo a Jerónimo, a quien devolvieron con sus padres, donde volvió a seguir sus costumbres y ley mahometana. Sin embargo, cuando era de edad de 25 años, en 1559, recibiendo la llamada de Cristo, huyó voluntariamente de su casa familiar a Orán, donde fue acogido con los brazos abiertos por parte de su antiguo amo, el cual llegó a casarlo con una moza cristiana, su esclava, que era de nación mora. Así vivió durante al menos 10 años, hasta que en mayo de 1569, Antón de Palma, adalid de la ciudad, con licencia del marqués de Cortes, don Martín de Córdoba, se embarcó con nueve compañeros, entre ellos Jerónimo, con el fin de robar a algunos árabes que vivían cerca de la marina. Sin embargo, una madrugada, mientras desembarcaban en aquel lugar, les dieron caza dos bergantines que venían de Tetuán y cautivaron a todos ellos, excepto a Antón de Palma, que logró escapar, aunque luego lo cogieron y tuvo que ser rescatado. A los otros nueve los condujeron hasta Argel, y como era costumbre que los reyes de Argel se quedasen, de cada diez cristianos, a dos de ellos para sí, Jerónimo y uno de sus compañeros fueron a parar al baño del entonces rey Euch Alí, renegado calabrés y general de la mar del Gran Turco. Al conocer el origen de Jerónimo, los morabutos trabajaron sin descanso para que volviera a su primigenia religión. A pesar de las amenazas y violencia física, Jerónimo se mantuvo firme en su fe cristiana hasta el punto de que se mostraba orgulloso de serlo y los instaba a seguir su ejemplo. Al conocer el monarca argelino esta situación, decidió causarle una cruel y notable muerte que sirviese de ejemplo a los cautivos cristianos. De este modo, ordenó al maestro de obras de un bastión que estaban construyendo a las afueras de la puerta de Babaluete, de nombre Micael, de origen navarro, que dejase un hueco vacío porque allí quería tapiar vivo a «aquel perro de Orán que no se quiere volver moro». 
Después de informar Micael a Jerónimo de la muerte que le esperaba, este oyó misa, se confesó con un sacerdote, tomó la comunión y aceptó resignadamente la hora de su muerte, que había de ser a mediados del mes de septiembre de 1569. Enviado ante el rey de Argel, un renegado español de Agi Morato, que en cristiano se decía Tamargo y en turco Jafer, cautivado en Mostagán con el conde de Alcaudete, fue el encargado de meterle en el hueco reservado para este martirio, llenándolo de tierra hasta tapiarlo vivo por completo:

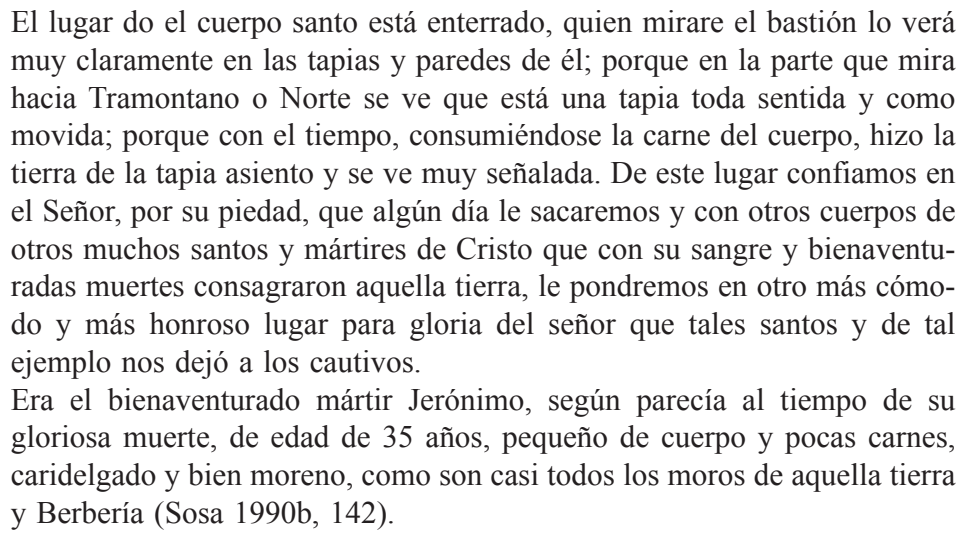

Como se ha podido ver, a partir de los comentarios de cada una de las entradas anteriores parece claro que la finalidad de este modelo era informar no solo sobre los sitios más emblemáticos de la ciudad, sino también sobre lugares estratégicos, especialmente aquellos que militarmente podían proporcionar una fuente de información muy valiosa ante la eventualidad de un ataque cristiano, como la situación de las murallas, sus puertas y torreones, los fuertes y palacios más importantes, el arsenal o el puerto. Era fundamental tener un conocimiento lo más exhaustivo posible de una ciudad que tantos quebraderos de cabeza estaba dando a la Monarquía Hispánica y para ello, informadores como Antonio de Sosa eran esenciales para saber cuáles eran los puntos débiles o fuertes de la ciudad.

Por desgracia, no contamos con el plano que el propio Sosa habría dibujado situando cada uno de los espacios señalados en este modelo, pero sí que existen distintos mapas de la época que nos ayudan a hacernos una idea de la exactitud de las noticias proporcionadas por el portugués, aunque ignoramos si pudieron llegar a sus manos.

Así, por ejemplo, antes de 1577, año del modelo que estamos comentando, existían ya algunas primeras representaciones manuscritas en portulanos o atlas que daban una idea aproximada del litoral africano y, por extensión, del argelino. A este respecto, tal y como se puede ver en el excelente trabajo de Epalza y Vilar (1988), algunos de los que diseñaron la orografía del norte de África, con mayor o menor exactitud, fueron Juan de la Cosa (1500), Juan 
Ortiz (1501), Waldssemüller (1507), Diego Ribeiro (1529) o Diego Homem (1561). Mapas que, por otro lado, sirvieron durante mucho tiempo a los marineros para navegar a lo largo del Mediterráneo.

En lo que a la imprenta se refiere, hubo también algunos acercamientos importantes que trataron de ilustrar con fidelidad el litoral africano, como son la Nova et Aucta Orbis Terrae Descriptio ad usum navigantium ementa et accomodata (1569), de Gerard Mercator, o el Theatrum orbis terrarum, de Abraham Ortelius (1588) -neerlandés al servicio de España que publica sus obras en Amberes, posesión española en Flandes-, libro que llegará a tener hasta 6 volúmenes con sucesivos añadidos, pero que hasta la fecha que nos ocupa solo vieron la luz los dos primeros, de 1570 y 1575 . En la edición de 1570 lleva el plano de «Berberia et Biledulgerid», que se repetirá en las posteriores ediciones y cuyo autor no se menciona. El modelo que sigue es el de Ptolomeo, aunque incluye algunas adaptaciones realizadas por algunos de los mejores cartógrafos de su tiempo.

No obstante, para nuestros intereses, habría que destacar los planos de la ciudad de Argel que, durante la segunda mitad del siglo XVI, fueron apareciendo tanto de manera impresa como manuscrita. Entre la primera forma de difusión, contamos con algunos ejemplos muy notables que aportan detalles cada vez más minuciosos sobre la configuración urbana de Argel. Tal es el caso del plano de la ciudad de Argel, de 1571, que «Marius Kartarius» imprimió en Roma y que, aunque muy inexacto en algunos detalles, fue utilizado para las galeras del rey de España en su deambular por el Mediterráneo y ya incluía una llave toponímica de la $\mathrm{A}$ a la $\mathrm{Z}$ en la parte inferior, situando los lugares más importantes de la urbe (Epalza y Vilar $1988,320-321)^{52}$. Sobre este modelo y con unas características semejantes surgirán otros mapas todavía más detallados. Entre ellos, cabe destacar, por su belleza y exactitud, el plano a color de Argel que Braun y Hogenberg incluyeron en su magnífico Civitate Orbis Terrarum. Liber secundus de praecipuis totuis universi urbibus liber secundus (Antuerpiae Coloniae Prostant, apud Philippum Gallaeum apud Auctores, ca. 1575), cuya llave toponímica aparece descrita en italiano, pero con una disposición semejante a la del modelo de Sosa, es decir, con letras en mayúsculas de la $\mathrm{A}$ a la Z y con números del 1 al 47 (Braun y Hogenberg 1575) $)^{53}$.

Entre los planos urbanos elaborados de forma manuscrita, en algunos casos por cautivos o excautivos procedentes de Argel, nos encontramos dibujos a plumilla como el conservado en el Archivo General de Simancas, de 1563 ${ }^{54}$, en donde se indican las puertas de acceso al recinto fortificado; o el descubierto recientemente en el Arquivo Nacional/ Torre do Tombo de Lisboa, perteneciente a la Casa de Cadaval, que representa a la «cidade de Argel

52. Mapa 404, pp. 320-321.

53. Ejemplar: Madrid. Biblioteca Nacional: GMG/44(2) PL. 59 Argel (Argelia).

54. AGS,MPD,7,131. 
fortificada, anno 1575». Dibujado por un portugués anónimo, presenta en la parte inferior derecha una cartela con una llave de topónimos de la A a la $Z^{55}$.

Similares a estos dos últimos tuvo que ser el que confeccionó Antonio de Sosa durante su cautiverio, cuyo valor, al igual que los anteriores, hay que buscarlo en el hecho de que fue diseñado por un cristiano que estaba cautivo allí y que tuvo la oportunidad de conocer de primera mano la configuración urbanística y militar de Argel. En una comparativa entre este plano y el de Braun/Hogenberg, veremos que aparecen con cierta exactitud todos los lugares que aquel indica:

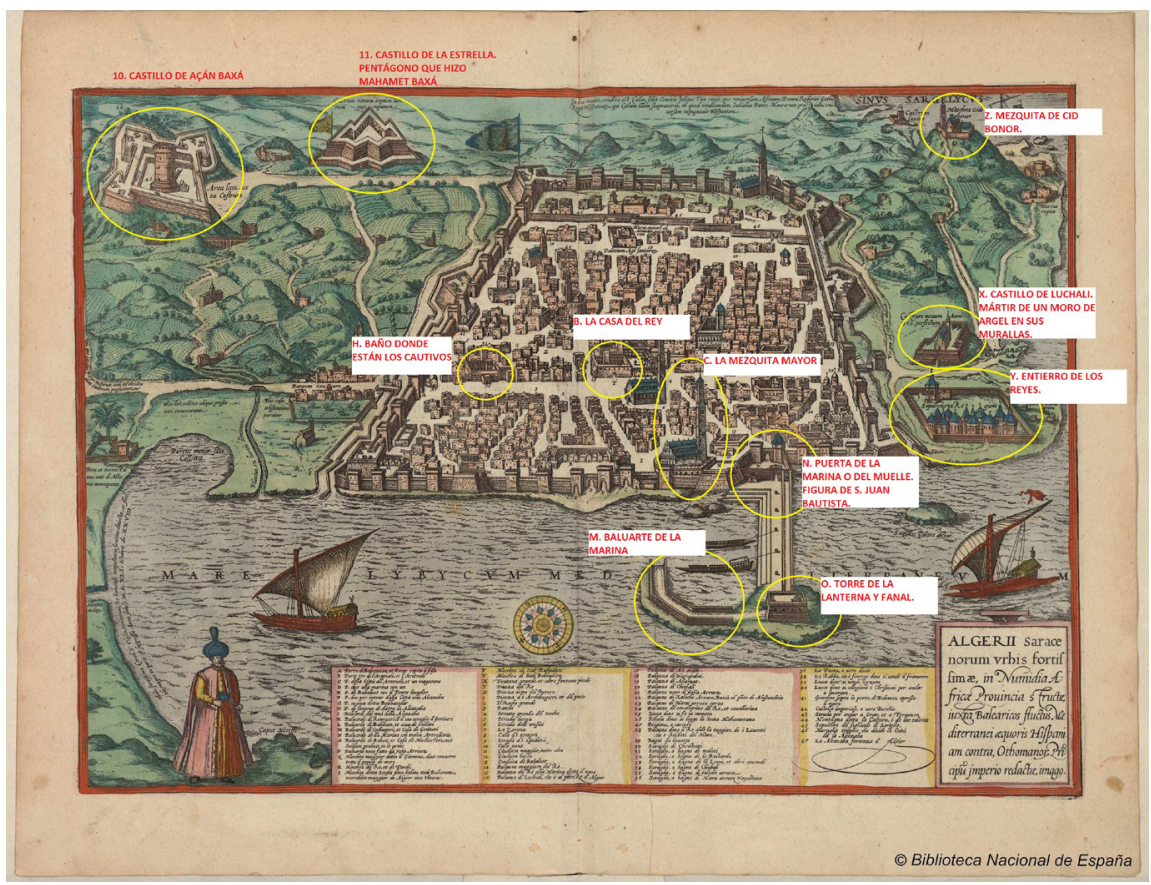

FiguRA 2. Plano de Argel (Braun y Hogenberg 1575). Ejemplar: Madrid: Biblioteca Nacional: GMG/44(2) PL. 59 Argel (Argelia).

Para finalizar, con la noticia de este hallazgo creemos haber arrojado nueva luz sobre uno de los personajes más fascinantes de cuantos compartió cautiverio con Miguel de Cervantes y que le habría podido servir de gran ayuda de no haber caído en desgracia. La importancia de los documentos que aquí hemos dado a conocer radica en que no solo aportan numerosas informaciones sobre la situación de Argel entre 1577 y 1578, sino que también

55. «Argel em 1575»: Lisboa. ANTT, Casa do Cadaval, n. ${ }^{\circ}$ 29, fol. 110. Ha sido expuesto recientemente en la muestra Entre a Cruz e o Crescente- $O$ resgate de cativos, que tuvo lugar en el Arquivo Nacional-Torre do Tombo de Lisboa, entre el 7 de marzo y el 7 de julio de 2018, bajo la dirección científica de Edite Martins Alberto. 
ayudan a atribuir de manera inequívoca la Topographia e historia general de Argel al portugués Antonio de Sosa. Es cierto que esta era una cuestión que había quedado resuelta en los últimos años, pero no lo es menos que se basaba en la trayectoria vital de Sosa y no en documentación como la que hemos presentado ahora, la cual, comparada con la Topographia e historia general de Argel, deja fuera de toda duda que se pueda atribuir a otra persona sino a Sosa.

En lo que respecta al texto correspondiente a la «Relación del número de vaxeles que al presente hay en Argel y andan en corso todo el año arruinando la Cristiandad, y de las personas que han llevado captivas al mismo Argel desde primero de abril de 1577 hasta onze de agosto 1578», así como al «Verdadero número de los captivos que las galeotas, vergantines y otros vaxeles de Argel han captivado desde primero de abril de 1577 hasta XI de agosto de $1578 »$, conservados ambos entre los folios 148r-151v del manuscrito Add. 28366 de la British Library, hemos demostrado que guardan vínculos evidentes de estructura y contenido con los capítulos 22 y 23 de la primera parte de la obra tradicionalmente atribuida a Diego de Haedo, es decir, la Topografía o descripción de Argel y sus habitadores y costumbres (1927a). De la autoría de estos dos textos no hay duda porque el nombre del doctor Sosa aparece en el sobrescrito, como tampoco la hay de otro texto anónimo, también conservado en el mismo manuscrito entre los folios $120 \mathrm{r}-121 \mathrm{v}$, que recoge un modelo de Argel cuya finalidad principal consistía en informar sobre los lugares más estratégicos de la ciudad, tal vez con vistas a un potencial ataque por parte de la Monarquía Hispánica. El contenido de la llave toponímica, con claros nexos con el capítulo 35 de la obra anterior así como, sobre todo, con el relato 17 del Diálogo de los mártires, nos han inducido a asignar su paternidad también al eclesiástico portugués.

Estos documentos demuestran un amplio y preciso conocimiento de la situación de Argel en dicho período de tiempo, con una exhaustividad de informaciones que hacen increíble que una persona como Sosa, fuertemente encadenado y privado de movimientos por parte de su amo, pudiera conseguirlas si no era a través de una red de informadores dentro de la misma ciudad que le proporcionase tal cantidad de datos ${ }^{56}$. Y dada la lucha que mantuvieron el rey Felipe II y el papa Gregorio XIII por hacerse con sus servicios, parece evidente que Sosa era un informador tanto de la corona como del sumo pontífice. Un informador de excepción que, en palabras de Sola y de la Peña $(1995,287)$, podría haber sido protegido por un agente secreto español renegado judío, es decir, su patrón Mahamet.

Aparte de ser de los pocos textos que se conocen de Antonio de Sosa durante sus cerca de cuatro años de cautiverio en Argel, es probable que documentos como estos fueran la base del borrón que pudo haber usado el abad

56. Emilio Sola y José Francisco de la Peña $(1995,157)$ plantean la posibilidad de que muchos de los soldados cautivos en Mostaganem junto al conde de Alcaudete, en 1558, hubieran sido la base de muchos de los informes recogidos por Sosa para su obra magna. 
Diego de Haedo para confeccionar el texto definitivo impreso en 1612 bajo el título de Topographia e historia general de Argel.

\section{BIBLIOGRAFÍA CITADA}

Astrana Marín, Luis. 1948-1958. Vida ejemplar y heroica de Miguel de Cervantes Saavedra. Madrid: Reus, 7 vols.

Bennassar, Bartolomé y Lucile Bennassar. 1989. Los cristianos de Alá: la fascinante aventura de los renegados, trad. José Luis Gil Aristu. Madrid: Nerea.

Braun, Georg y Frans Hogenberg. 1575. «Plano de Argel». En Civitate Orbis Terrarum ([s.1.], [s.e.]). Ejemplar: Madrid: Biblioteca Nacional: GMG/44(2) PL. 59 Argel (Argelia).

Braun, Georg y Frans Hogenberg. ca. 1575. «Plano de Argel». En Civitate Orbis Terrarum. Liber secundus de praecipuis totuis universi urbibus liber secundus. Antuerpiae Coloniae Prostant: apud Philippum Gallaeum apud Auctores. Ejemplar: Madrid: Biblioteca Nacional: GMG/44(2) PL. 59 Argel (Argelia).

Camamis, Georges. 1977. Estudio sobre el cautiverio en el Siglo de Oro. Madrid: Gredos.

Cervantes, Miguel de. 1863-1864. Don Quijote de la Mancha, ed. Juan Eugenio Hartzenbusch. Argamasilla de Alba: Imprenta de don Manuel de Rivadeneyra.

Contreras, Alonso de. 1988. Vida del capitán Contreras, ed. Henry Ettinghausen. Madrid: Espasa - Calpe.

Dan, Pierre. 1649a. Histoire de Barbarie et de ses corsaires, des royaumes et des villes d'Alger, de Tunis. París: chez Pierre Rocolet.

Dan, Pierre. 1649b. Histoire de Berbérie et des corsaires des royaumes et des villes d'Alger, de Tunis, de Salé et de Tripoli. París: Pierre Rocolet, 2. ${ }^{\mathrm{a}}$ ed.

Dan, Pierre. 1884. Les illustres captifs. Manuscrit du Père Dan, analysé par Louise Piesse et Henri Delmas de Grammont. Argel: Adolphe Jourdan, Libraire - Éditeur, Imprimeur - Libraire de 1'Academie.

Denis, Ferdinand. 1858. «Haedo (Fray Diego de)». En Nouvelle biographie générale, dir. Monsieur le Dr. Hoefer, XXIII, 50-52. París: Firmin Didot Frères.

Eisenberg, Daniel. 1996. «Cervantes, autor de la Topografia e historia general de Argel publicada por Diego de Haedo». Cervantes: Bulletin of the Cervantes Society of America 16(1): 32-53.

Entre a Cruz e o Crescente- O resgate de cativos, dir. Edite Martins Alberto. Lisboa. Arquivo Nacional - Torre do Tombo de Lisboa. Exposición entre 7 de marzo y 7 de julio de 2018.

Epalza, Mikel de y Juan Bautista Vilar. 1988. Planos y mapas hispánicos de Argelia, siglos XVI-XVIII. Madrid: Instituto Hispano-Árabe de Cultura.

Galán, Diego. 2001. Relación del cautiverio y Libertad de Diego Galán, natural de la villa de Consuegra y vecino de la ciudad de Toledo, eds. Miguel Ángel de Bunes y Matías Barchino. Toledo: Diputación Provincial de Toledo.

Galarreta-Aima, Diana. 2015. "Topografia e historia general de Argel: testimonio de un cautivo desde el otro lado del Mediterráneo». eHumanista: Journal of Iberian Studies 30: $260-274$.

Garcés, María Antonia. 2005a. «La Información de Argel: un acto de testimonio». En Cervantes en Argel: historia de un cautivo, 208-211. Madrid: Gredos.

Garcés, María Antonia. 2005b. Cervantes en Argel: historia de un cautivo. Madrid: Gredos. 
Garcés, María Antonia. 2011. An early Modern Dialogue with Islam. Antonio de Sosa's Topography of Algiers (1612), trad. Diana de Armas Wilson. Indiana: University of Notre Dame Press.

Garcés, María Antonia. 2012. «Carta de Juan de Bolaños y Antonio de Sosa presentando a Mateo Vázquez la relación de avisos de Luis Fresco Brevez». Archivo de la Frontera. Accesible en: <http:/www.archivodelafrontera.com/wp-content/uploads/2012/03/ Garc\%C3\%A9s-Sosa-y-Bola\%C3\%B1os-carta.pdf $>$. Fecha de acceso: 8 de abril de 2021.

Garcés, María Antonia. 2017. «Antonio de Sosa». En Christian-Muslim Relations 1500 1900, ed. David Thomas, 120-124. Leiden - Boston: Brill.

Gayangos, Pascual de, ed. 1875. Memorias del cautivo en la Goleta de Túnez (El alférez Pedro de Aguilar), del original en poder de Tyssen Amhurst, Esq.re., de Didlington Hall, Norfolk. Madrid: Sociedad de Bibliófilos Españoles.

Gayangos, Pascual de. 1875-1893. Catalogue of Spanish manuscripts in the Spanish Language in the British Museum, vol. III(53), 773. Londres: Printed by Order of the Trustees, 4 vols.

González Castrillo, Ricardo 2011. «Cautivos españoles evadidos de Constantinopla en el siglo XVI». Anaquel de Estudios Árabes 22: 265-278.

Gonzalo Sánchez-Molero, José Luis. 2010. La Epístola a Mateo Vázquez: historia de una polémica literaria en torno a Cervantes. Alcalá de Henares: Centro de Estudios Cervantinos.

Grammont, Henri Delmas de, trad. 1881. Histoire des rois d'Alger. Argel: Adolphe Jourdan.

Haedo, Diego de. 1612. Topografia e historia general de Argel. Valladolid: Diego Fernández de Córdova y Oviedo, a costa de Antonio Coello.

Haedo, Diego de. 1870-1871. Topographie, trad. Docteur Monnereau y Adrien Berbrugger. Revue Africaine (80-81): 490-519.

Haedo, Diego de. 1927-1929. Topografía e historia general de Argel, ed. Ignacio Bauer y Landauer. Madrid: Sociedad de Bibliofilos Españoles, 3 vols.

Haedo, Diego de. 1927a. «Topografía o descripción de Argel y sus habitadores y costumbres». En Topografia e historia general de Argel, ed. Ignacio Bauer y Landauer, I: 15-212. Madrid: Sociedad de Bibliófilos Españoles.

Haedo, Diego de. 1927b. «Epítome de los reyes de Argel». En Topografía e historia general de Argel, ed. Ignacio Bauer y Landauer, I: 213-426. Madrid: Sociedad de Bibliófilos Españoles.

Haedo, Diego de. 1929a. «Diálogo primero. De la captividad en Argel». En Topografía e historia general de Argel, ed. Ignacio Bauer y Landauer, II: 1-216. Madrid: Sociedad de Bibliófilos Españoles.

Haedo, Diego de. 1929b. «Diálogo segundo. De los mártires de Argel». En Topografía e historia general de Argel, ed. Ignacio Bauer y Landauer, III: 1-192. Madrid: Sociedad de Bibliófilos Españoles.

Haedo, Diego de. 1929c. «Diálogo tercero. De los morabutos de Argel». En Topografía e historia general de Argel, ed. Ignacio Bauer y Landauer, III: 193-274. Madrid: Sociedad de Bibliófilos Españoles.

Herrero García, Miguel. 1925. «Morato Arráez». En Homenaje ofrecido a D. Ramón Menéndez Pidal. Miscelánea de estudios lingüísticos, literarios e históricos, II: 323-329. Madrid: Edit. Hernando.

Herrero García, Miguel. 1926. «Morato Arráez». Revista de Filología Española 13(2): 179-182.

Lucía Megías, José Manuel. 1999. «La pragmática de 1558 o la importancia del control del estado en la imprenta española». Revista de Historia y Arte 4 (in memoriam José Francisco de la Peña Gutiérrez): 195-220. 
Lucía Megías, José Manuel. 2016. La juventud de Cervantes. Una vida en construcción (1547-1580). Madrid: Edaf.

Marín Cepeda, Patricia. 2010. «Cuatro personajes en busca de autor para la Topografía e Historia general de Argel: Haedo (Arzobispo de Sicilia), Haedo (Abad de Frómista), Sosa y Cervantes». En Hos ergo versículos feci... Estudios de atribución y plagio, ed. Javier Blasco, Patricia Marín Cepeda y Cristina Ruiz Urbón, 103-140. Madrid Frankfurt: Iberoamericana - Vervuert.

Marín Cepeda, Patricia. 2015. Cervantes y la corte de Felipe II. Escritores en el entorno de Ascanio Colonna (1560-1608). Madrid: Polifemo (colección «La Europa de la Corte», vol. 14).

Mateu Ibars, Josefina. 1963. Los virreyes de Valencia. Fuentes para su estudio, 163-172. Valencia: Ayuntamiento.

Mercator, Gerard. 1569. Nova et Aucta Orbis Terrae Descriptio ad usum navigantium ementa et accomodata. Bruselas: J. Pilliet, succrs. P. J. Voglet. Ejemplares: Madrid. Biblioteca Nacional. Signatura: Sala Goya, GMM 39.

Morgan, Joseph. 1728-1729. A complete History of Algiers to which is prefixed an Epitome of the General History of Barbary, from the earliest times. Londres: James Bettenham, 2 vols.

Morgan, Joseph. 1731. A complete History of Algiers, to which is prefixed a Epitome of the General History of Barbary, from the earliest times. Londres: James Bettenham.

Mounir Salah, Mohamed. 1992. El Doctor Sosa y la Topografía e Historia General de Argel. Barcelona: Publicacions de la Universitat Autònoma, Bellaterra.

Ortelius, Abraham. 1588. Theatro del orbe de la tierra. Amberes: Librería Plantiniana, $\mathrm{GMg} / 1022$.

Parreño, José María. 1990. «Experiencia y literatura en la obra de Antonio de Sosa». En Antonio de Sosa, Diálogo de los mártires de Argel, 9-23. Madrid: Hiperión.

Pérez Pastor, Cristóbal. 1897-1902. Documentos cervantinos hasta ahora inéditos. Madrid: Establecimiento Tipográfico de Fortanet, 2 vols.

Pirri, Rocco. 1633-1647. Sicilia Sacra disquisitionibus et notitijs illustrata: ubi libris quatuor postquam de illius patriarchia, et metropolita disquisitum est, à christiane religionis exordio ad nostra usque tempora cuiusque praesulatus, maiorumque beneficiorum institutio, archiepiscopi, episcopi, abbates, priores, singulorum iura, priuilegia, praeclara monumenta, ciuitates dioeceseon cum praecipuis earum templis, religiosisque familijs atque viri siculi vel sanctitate, vel doctrina illustres continentur, explicantur, lib. III, XC, fol. 641. Palermo: Ex tipographia Petri Coppulae. Syracusanae Ecclesie Notitia II.

Providence, Calixte de la. 1892. Les plus illustres captifs ou Recueil des Actions hérö̈ques d'un grand nombre de Guerriers et autres chrétiens réduits en esclavage par les Mahométans. Manuscrit de la Bibliothèque Mazarine, édité intégralement pour la première fois. Lyon - París: Delhomme et Briguet éditeurs, 2 vols.

Rico, Francisco. 2014. «Vislumbres de un poema autógrafo de Miguel de Cervantes a Antonio Veneziano». En Aurea poesis: estudios para Begoña López Bueno, eds. Luis María Gómez Canseco, Juan Montero Delgado y Pedro Ruiz Pérez, 141-148. Córdoba: Universidad - Universidad de Sevilla, Secretariado de Publicaciones - Universidad de Huelva.

Ruta, Maria Caterina 1979. «Le ottave di Cervantes per Antonio Veneziano e Celia». Bolletino del Centro di Studi filologici e linguistici siciliani 14(17): 171-185.

Sola Castaño, Emilio. 1988. «Miguel de Cervantes, Antonio de Sosa y África». En Actas del I Encuentro de Historiadores del Valle del Henares, 617-623. Alcalá de Henares: Institución de Estudios Complutenses - Fundación Marqués de Santillana - Centro de Estudios Saguntinos. 
Sola Castaño, Emilio. 1990. «Un clásico inédito amigo de Cervantes (historia y literatura)». En Actas del I Coloquio Internacional de la Asociación de Cervantistas, 409-412. Barcelona: Anthropos.

Sola, Emilio y José Francisco de la Peña. 1995. Cervantes y la Berbería. Cervantes, mundo turco-berberisco y servicios secretos en la época de Felipe II. México - Madrid: Fondo de Cultura Económica.

Sola, Emilio, trad. y María Antonia Garcés, ed. 2012. «Una espléndida relación de avisos: Relación de las cosas sucedidas en Argel... (1581), de Luis Brevez Fresco». Archivo de la Frontera. Accesible en: <http://www.archivodelafrontera.com/archivos/unaesplendida-relacion-de-avisos-de-1581-de-un-mercader-y-espia-genoves/>. Fecha de acceso: 8 de abril de 2021.

Sosa, Antonio de. 1990. Diálogo de los mártires, eds. Emilio Sola y José Maria Parreño. Madrid: Hiperión.

Sosa, Antonio de. 2014. «Declaración del doctor Antonio de Sosa». En Pina Rosa Piras, La «Información en Argel» de Miguel de Cervantes: entre ficción y documento, 146151. Alcalá de Henares: Centro de Estudios Cervantinos.

Vargas Díaz-Toledo, Aurelio. 2012. "Análisis de un texto portugués sobre el Quijote: la Relaçam de tudo o que sucedeu no sítio e defensa da grande cidade de Praga». Anales Cervantinos 44: 285-314. https://doi.org/10.3989/anacervantinos.2012.015

Vargas Díaz-Toledo, Aurelio. 2015. «Novedades en torno al estudio de Cervantes en Portugal: siglos XVII y XVIII». Revista Cálamo FASPE 64: 82-91.

Vargas Díaz-Toledo, Aurelio. 2018a. «El entorno portugués de Cervantes». En Cervantes e Portugal: História, Arte e Literatura, eds. Aurelio Vargas Díaz-Toledo y José Manuel Lucía Megías, 139-166. Oporto: Estratégias Criativas - Fundação Calouste Gulbenkian.

Vargas Díaz-Toledo, Aurelio. 2018b. «Rescate de una edición olvidada del Quijote (Lisboa, à custa de los hermanos Du Beux, Lagier \& Socios, 1775)». Hipogrifo. Revista de literatura y cultura del Siglo de Oro 6(2): 311-335.

Vargas Díaz-Toledo, Aurelio. 2019. «En torno a Manuel de Sousa Coutinho, compañero de cautiverio de Cervantes: reconstrucción de su vida». En Cervantes y los mares. En los 400 años del «Persiles». In memoriam José María Casasayas, ed. Maria Fernanda de Abreu, 85-119. Berlín - Berna - Bruselas - Nueva York - Oxford - Varsovia: Peter Lang.

Recibido: 7 de septiembre de 2020

Aceptado: 5 de febrero de 2021 